Research Article

\title{
Shear Bearing Capacity of Framework Joints of Steel-Reinforced Concrete-Filled Circular Steel Tube
}

\author{
Yongjun Lin (D), Kaiqi Liu, Tianxu Xiao, and Chang Zhou \\ School of Civil Engineering, Southwest Jiaotong University, Chengdu 610031, China \\ Correspondence should be addressed to Yongjun Lin; scsmith@126.com
}

Received 11 September 2019; Revised 21 December 2019; Accepted 27 December 2019; Published 16 January 2020

Academic Editor: Fernando Lusquiños

Copyright ( $\odot 2020$ Yongjun Lin et al. This is an open access article distributed under the Creative Commons Attribution License, which permits unrestricted use, distribution, and reproduction in any medium, provided the original work is properly cited.

In this paper, in order to investigate the shear mechanism and shear capacity of framework joints of steel-reinforced concretefilled circular steel tube (SRCFCST), a numerical finite element model reflecting the mechanical behavior of framework joints of SRCFCST column-reinforced concrete beam is established through simulating concrete by the damage plastic constitutive model and simulating steel by the ideal elastic-plastic material, and its effectiveness is verified by experimental data. On account of uniform distribution of circular steel reinforced around the section and without definite flange and web, the shear mechanism of the framework joints of SRCFCST is analyzed on the basis of equivalent circular steel tube (CST) to the rectangular steel tube. The method for calculating the superposed shear bearing capacities of the joint core area is proposed, which is composed of four parts, i.e., concrete inside tube, concrete outside tube, hooping and steel-reinforced web; and the corresponding formulas for calculating shear bearing capacity are established. The comparative analysis of joints' shear bearing capacity indicates that the results of numerical simulation and shear bearing capacity formulas coincide well with the experimental values, which can provide reference for the nonlinear analysis and engineering design of similar joints.

\section{Introduction}

Steel-reinforced concrete structure is a structure composite of steel and reinforced concrete, abbreviated to SRC structure. In SRC columns, steel and concrete work together, which not only has favorable antiseismic and durability performance but also can relatively reduce costs. At present, it has been widely applied in high-rise buildings around the world $[1,2]$.

There are different forms of section steel in SRC structures, e.g., lattice section steel, H-type section steel, cross section steel (general SRC), and circular steel tube (CST). Compared to general SRC structure, the CST-reinforced tube in SRC columns has the advantages of simple and easy fabrication, and steel is evenly distributed around the section, which is very beneficial to the corner columns bearing biaxial bending. At the same time, the three-dimensional restraint effect of steel tube on inner-core concrete can also develop the potential of steel and concrete more effectively [3]. However, at present, the researches on SRC structure mainly focus on general SRC structure, and few have been carried out on the SRCFCST structure [4].
The joints are the key parts connecting frame columns and beams. Under earthquake action, in order to meet the structural design requirements of "strong joints, weak members," the shear force bore by internal joints is even several times larger than that of the beams and columns $[5,6]$. To this end, some scholars have conducted a lot of research on the shear mechanism and shear capacity of framework joints, but which were mainly for framework joints of reinforced concrete and general SRC [7-10]. Chen et al. [11] and Han and Li [12] studied the seismic behaviour of concrete-filled steel tubular (CFST) joints considering the effect of the slab. The slab effect on the shear transfer in the panel zone is investigated as well. Zhang et al. [13] experimentally investigated the behaviour of ring beam joints between concrete-filled twin steel tubes columns and reinforced concrete beams. The test results showed that the joints with good aseismatic behavior can easily achieve the antiseismic design principles, namely, "strong column-weak beam" and "strong joint-weak member." Finite element modeling was also implemented to conduct some parametric analyses. Han et al. [14] conducted experiments on thin-walled steel tube 
confined concrete (TWSTCC) column to reinforced concrete beam joints subjected to cyclic loading and found that the TWSTCC joints show generally excellent seismic performance and is adoptable in practical engineering, particularly in earthquake zone. Nie et al. [15] proposed a new connection system for a concrete-filled steel tube composite column and reinforced concrete beams and analyzed the mechanical properties of this type of connection under the action of seismic load and found that the effective confinement can be achieved by the stiffening ring, and an excellent axial bearing capacity can be obtained, as well as a superior ductility and energy dissipation capacity. Chen et al. [16] aimed to investigate the seismic behaviour of a through-beam connection between concrete-filled steel tubular columns and reinforced concrete beams, and cyclic loading tests and subsequent axial compressive tests are reported on six beam-column specimens. A finite element model is also developed and validated by a comparison with the experimental results. Ding et al. [17] conducted a cyclic loading test on a group of nonthrough-core connection, established the finite element model for calculation and analysis, discussed its strain curve, ductility curve, stiffness degradation curve, and energy dissipation curve, and concluded that SRCFCST joints had better seismic performance than ordinary reinforced concrete beam-column joints. Liao et al. [18] established seven composite joint models, including four concrete-encased CFST columns to RC beam joints and three concrete-encased CFST columns to steel beam joints, and then models were tested and compared under constant axial load on the top of the column and cyclic load at the end of the beam. Based on the test results, the strength, ductility, rigidity degradation, and dissipated energy of the specimens were investigated. However, there are few studies on the shear resistance of framework joints of SRCFCST, and its shear mechanism also needs to be further improved [19]. In this paper, a numerical finite element model is established to simulate the mechanical behavior of SRCFCST columnframework joints of the reinforced concrete beam; and its effectiveness is verified by the results of low-cycle repetitive loading experiments in [3]. On account of uniform distribution of circular steel reinforced around the section and without definite flange and web, the shear mechanism of concrete inside tube, concrete outside tube, hooping, and steel-reinforced web in joint core area is analyzed on the basis of equivalent CST to the rectangular steel tube; and the formulas for calculating the superposed shear bearing capacities of the joint core area is proposed. The comparative analysis of joints' shear bearing capacity indicates that the results of numerical simulation and shear bearing capacity formulas coincide well with the experimental values, which can provide reference for the nonlinear analysis and engineering design of similar joints.

\section{Numerical Finite Element Model}

2.1. Constitutive Relation of Materials. Under the action of cyclic load, the cyclic strengthening effect of steel (including section steel and reinforcing steel bar) will cause it to generate greater strain than that under unidirectional load, which makes the strengthening effect of steel not obvious when the core area reaches the ultimate bearing, while the concrete in the core area may have been destroyed [20]. Therefore, in numerical simulation, the strengthening effect of steel could be neglected, and the ideal elastic-plastic model can be adopted.

For SRCFCST columns, the concrete in joints' core area can be divided into the concrete outside steel tube and concrete inside steel tube. The restraint effects on the two are different. The test results indicate that the restraint on the latter one is greater than that on the former one. However, according to the experimental results, when destroyed, the concrete on the side of joint area has peeled off, while the concrete inside the steel tube has not been destroyed [19], which shows that the restraint effects on concrete inside the steel tube of SRCFCST column is less than that of the concrete-filled steel tube in limit state [3]. This is because the stress in the steel tube of concrete-filled structure will reach the yield strength in the failure stage while experiments show that the failure of the SRCFCST structures is due to the yielding of the reinforcements around the steel tube, and the steel tube has not yet yielded at this stage, which leads to the effect on the inside concrete smaller than that of concretefilled steel tube structures.

Moreover, under cyclic loads, the "plastic deformation" in traditional sense accounts for a small proportion of inelastic deformation of concrete $[21,22]$. Therefore, the same constitutive relationship can be utilized for concrete inside and outside the steel tube in numerical simulation. In this paper, the damage-plasticity model is adopted for concrete, which applies the isotropic elastic damage and takes the degradation of elastic stiffness caused by plastic strain under tension compression and stiffness recovery under cyclic loads into account so that it can accurately simulate the mechanical behavior of concrete under cyclic.

Under cyclic loads, the damage mechanics characteristics of concrete are related to the opening and closing of internal microcracks and their interaction. The model assumes that the modulus of elasticity after damage can be expressed as the relationship between the initial elasticity modulus with the damage factor, i.e.,

$$
E_{\mathrm{dam}}=(1-d) E_{0},
$$

where $E_{0}$ is the initial elastic modulus of concrete, $E_{0}$ is the elastic modulus of concrete after damage, and $d$ is the damage factor, which can be divided into compressive damage factor $d_{\mathrm{c}}$ and tensioned damage factor $d_{\mathrm{t}}$.

Since the tensile strength of concrete is much lower than the compressive strength and also has small influence on the structure, the influence of tensile damage coefficient of concrete is not considered in this paper. The compressive damage factor of concrete can be calculated by classical damage theory, and the calculation formulas are as follows [23]:

$$
d_{\mathrm{c}}=\frac{E_{\mathrm{c}, 0} \varepsilon_{\mathrm{c}}^{2}-2 \int \sigma_{\mathrm{c}}\left(\varepsilon_{\mathrm{c}}\right) d \varepsilon_{\mathrm{c}}}{E_{\mathrm{c}, 0} \varepsilon_{\mathrm{c}}^{2}},
$$

where $E_{c, 0}$ is the initial compressive elastic modulus of concrete; $\varepsilon_{\mathrm{c}}$ is the compressive strain of concrete; and $\sigma_{\mathrm{c}}\left(\varepsilon_{\mathrm{c}}\right)$ is the uniaxial compressive constitutive function of concrete. 
Under cyclic loads, the formula for calculating compressive plastic strain of concrete in consideration of compressive damage is as follows:

$$
\widetilde{\varepsilon}_{\mathrm{c}}^{\mathrm{pl}}=\varepsilon_{\mathrm{c}}-\frac{d_{\mathrm{c}} \sigma_{\mathrm{c}}}{\left(1-d_{\mathrm{c}}\right) E_{\mathrm{c}, 0}},
$$

where $\widetilde{\mathcal{E}}_{\mathrm{c}}^{\mathrm{pl}}$ is the compressive plastic strain of concrete in consideration of compressive damage.

The uniaxial compression (tension) stress-strain relationship curve recommended in GB50010-2010 Code for Design of Concrete Structures is adopted, which consists of three parts: elastic, strengthening, and softening [24].

\subsection{Numerical Model}

2.2.1. Unit Partition. The whole geometric model of framework joint SRCFCST column-reinforced concrete beams studied in this paper is shown in Figure 1 [19].

The numerical analysis is carried out by ABAQUS, a large-scale general-purpose nonlinear finite element analysis software; and the finite element model of framework joints is established. The eight-joint hexahedron element (C3D8R) is used for steel tube and concrete, which can make the Gauss integral points satisfy that required for accurate integration, and the hourglass control can be conducted. Two-joint three-dimensional truss element (T3D2) is used for beam, column longitudinal reinforcement, and hooping. Steel tube and concrete elements are divided into regular hexahedron by the mapping grid. In consideration of the research focus of joints, the grid in the joints' core area is densified.

The bond-slip characteristics between steel tube and concrete, and between reinforcing bar and concrete, are not considered in the finite element model but sticked together directly, assuming that there is the same displacement on their common interface. The bond constraints between steel tube with concrete inside and outside are carried out by ${ }^{*}$ TIE Command; and beams, columns, and hooping are placed in concrete by ${ }^{*}$ EMBEDED Command.

2.2.2. Boundary Conditions and Loading Mode. Vertical, horizontal, and rotational constraints are imposed on the bottom of column; the horizontal and rotational constraints are imposed on the top of column; then the fixed axial force $N$ is imposed on the top of column to simulate vertical loads; and the cyclic concentrated loads $P$ or cyclic vertical displacement $\Delta$ with equal magnitude and opposite direction is applied on both ends of the beam to simulate the horizontal seismic action (load loading is used before the longitudinal reinforcement yields, and displacement loading is used after yielding).

\section{Joint Model Experiment and Numerical Simulation}

\subsection{Model Experiment}

3.1.1. Experiment Joint Model. There are three groups of specimens in the test model, i.e., nonperforated specimens

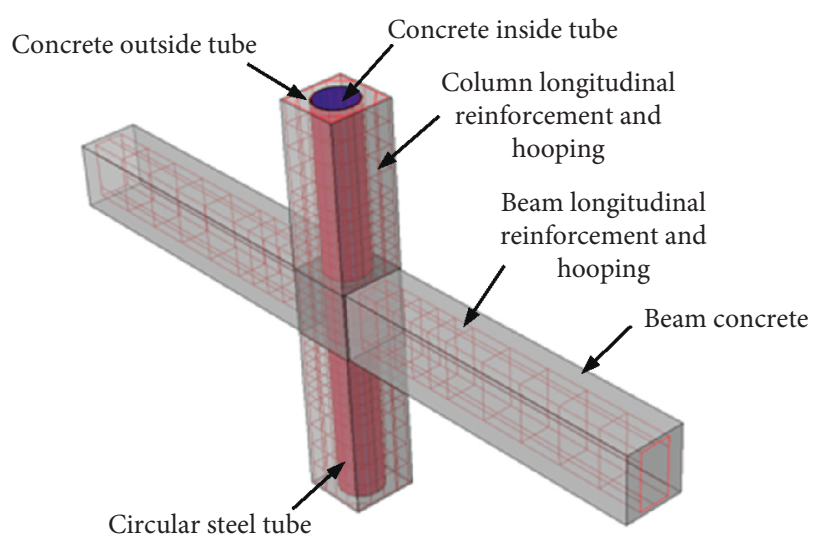

Figure 1: Whole geometric model of framework joint.

(Group A), reinforcement-perforated specimens (Group B), and large-hole specimens (Group C), and two specimens in each group, six specimens in total. The three groups only differ on the way of opening on the steel tube at the joints. The upper and lower longitudinal reinforcements of each specimen beam are 5B22 and arranged in two rows, $3 \mathrm{~B} 25$ for the outer row and 2B25 for the inner row. The details are as follows:

(1) Nonperforated Specimen. Only one longitudinal reinforcement in the middle of outer row passes through a small circular hole with a diameter of $26 \mathrm{~mm}$ in the CST, and the rest passes through the outside of the steel tube, which is similar to nonperforation.

(2) Reinforcement-Perforated Specimens. Small circular holes with a diameter of $26 \mathrm{~mm}$ are opened at the intersection of the upper and lower longitudinal reinforcements of beams with steel tube, and all the longitudinal reinforcement passes through the steel tube from these holes.

(3) Large-Hole Specimens. A $166 \mathrm{~mm} * 72 \mathrm{~mm}$ rectangular hole is opened at the intersection of the upper and lower longitudinal reinforcements of beams with steel tube in column. All the longitudinal reinforcement passes through the steel tube from the large hole, which is called large-hole specimens.

As the experiment is carried out to acquire the failure mechanism of the joints, the specimens are designed according to the principle of "weak joints, strong members." The strength grade of concrete is C40, the longitudinal reinforcement is HRB335 reinforcing bar, the hooping is HPB235 reinforcing bar, and the steel tube in column is rollwelded by Q235 steel. The size, rebars, and structure of specimens are shown in Figure 2 and Table 1, and the material properties are shown in Tables 2 and 3.

\subsubsection{Experiment Device, Loading Program, and Measuring}

Points. The experiment loading device is shown in Figure 3. The predetermined axial force of $1000 \mathrm{kN}$ is applied at the end of column and kept constant, with an axial compression ratio of about 0.3 . The lower cyclic repetitive concentrated 


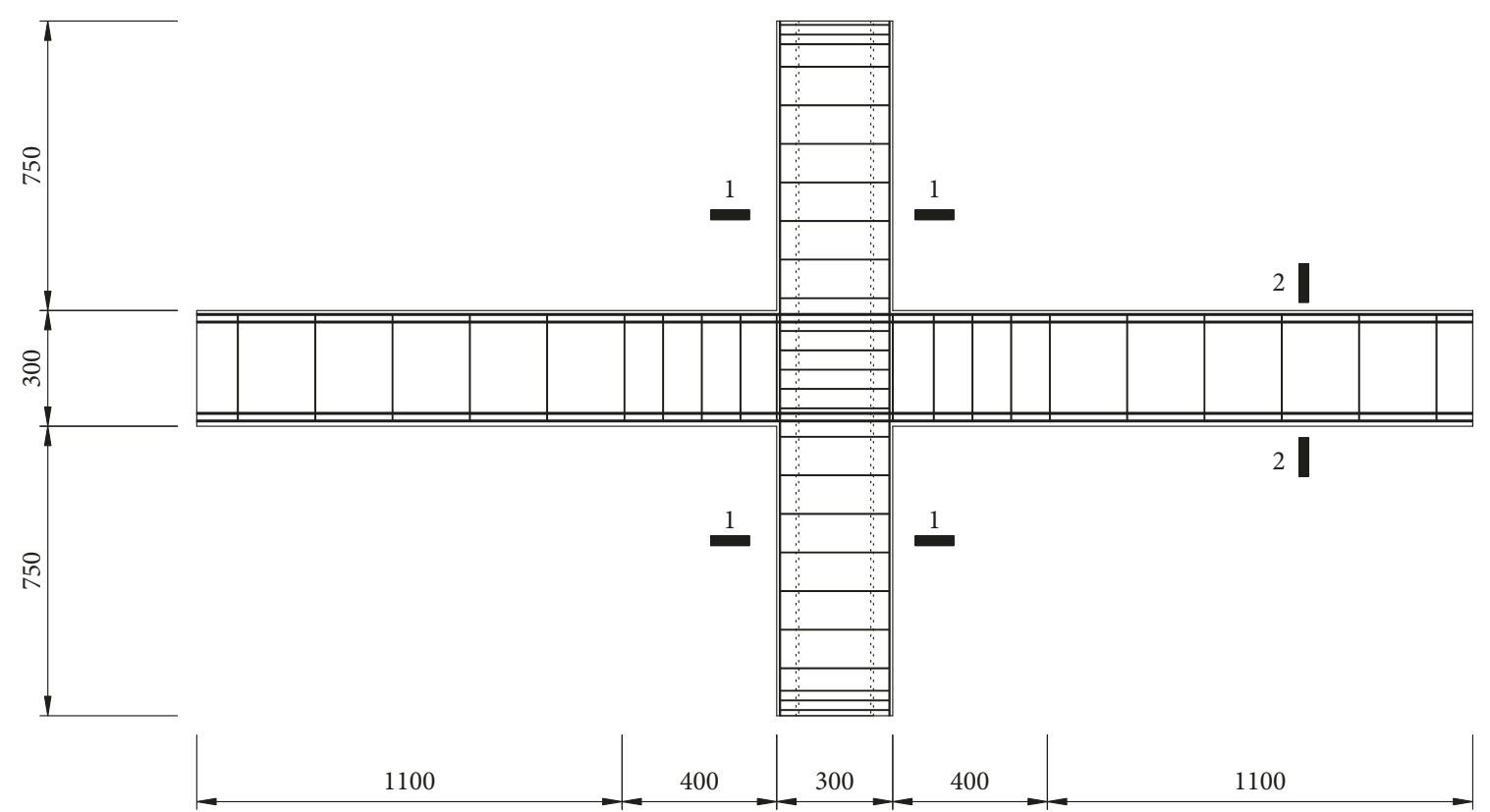

(a)
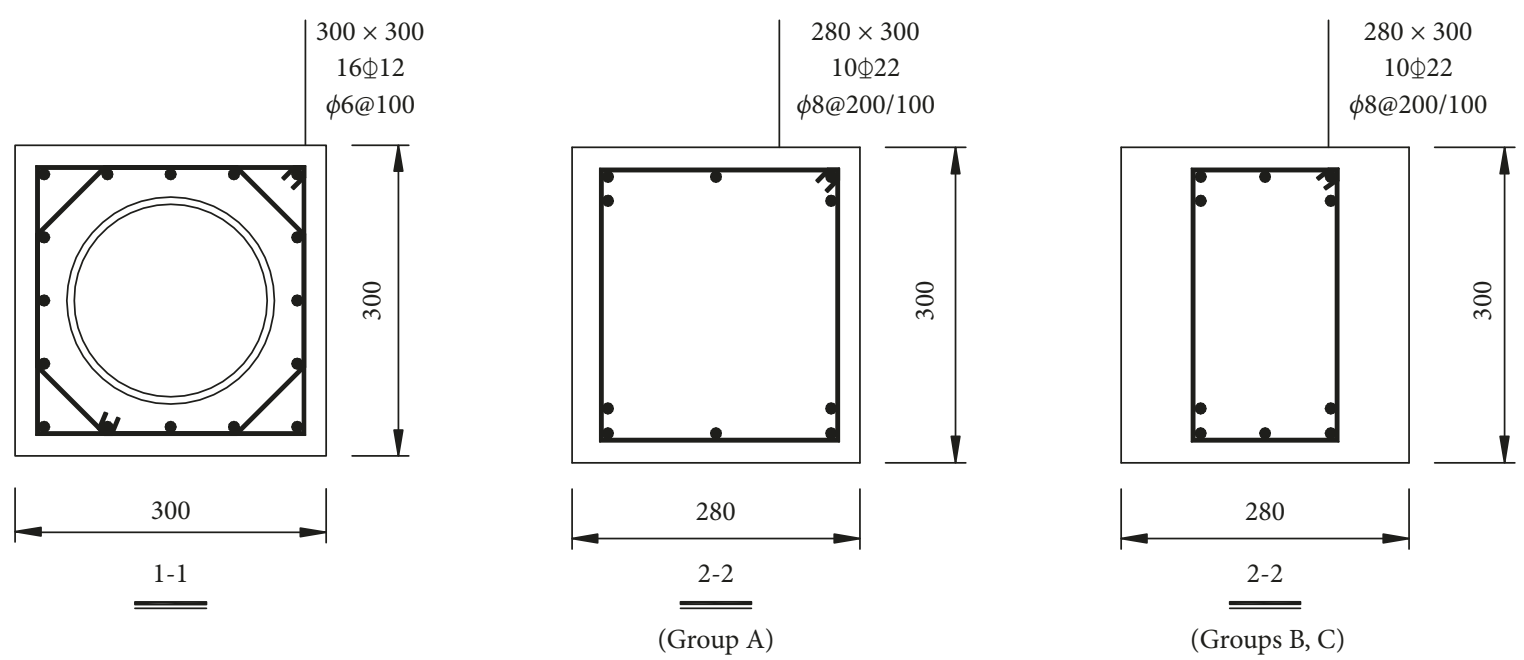

(b)
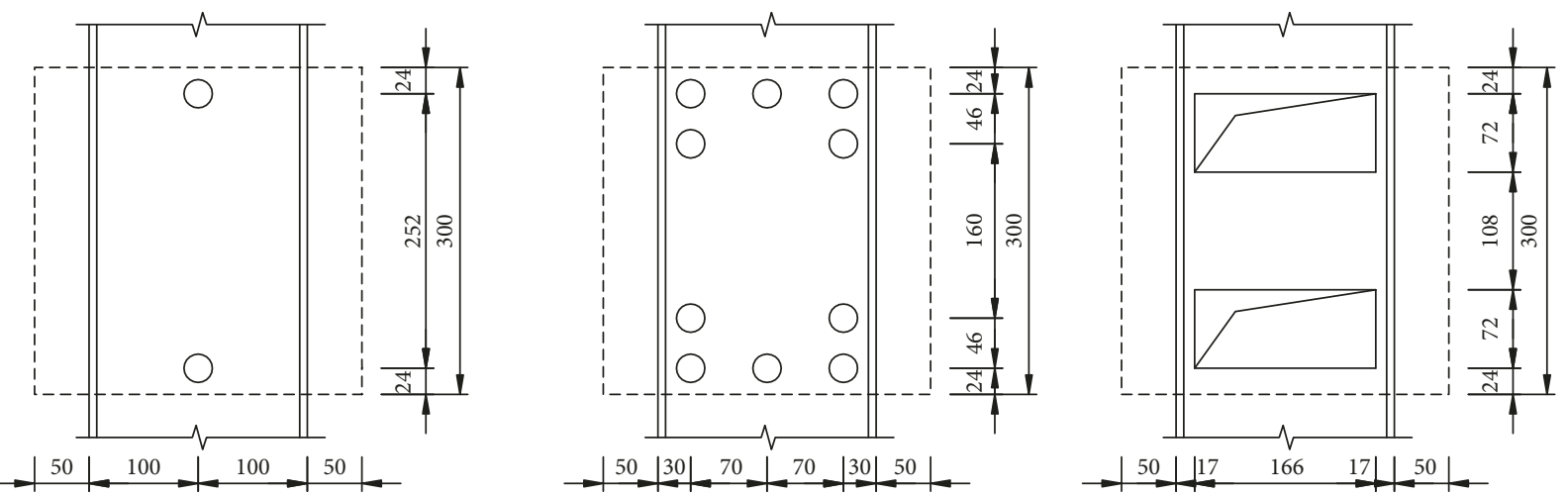

(c)

FIgURE 2: Size and structure of specimens. (a) Specimen size. (b) Section construction of column and beam. (c) Opening hole type of steel tube. 
TABLE 1: Size and structure of specimens.

\begin{tabular}{|c|c|c|c|c|c|c|c|c|}
\hline \multirow[b]{2}{*}{$\begin{array}{l}\text { Specimen } \\
\text { no. }\end{array}$} & \multicolumn{4}{|c|}{ Column } & \multicolumn{4}{|c|}{ Beam } \\
\hline & $\begin{array}{l}B \times h \\
(\mathrm{~mm})\end{array}$ & $\begin{array}{l}\text { Longitudinal } \\
\text { reinforcement }\end{array}$ & $\begin{array}{l}\text { Steel reinforced } \\
D \times t(\mathrm{~mm})\end{array}$ & Hooping & $\begin{array}{c}b \times h \\
(\mathrm{~mm})\end{array}$ & $\begin{array}{l}\text { Longitudinal } \\
\text { reinforcement }\end{array}$ & Hooping & $\begin{array}{l}\text { Hooping in joint } \\
\text { core area }\end{array}$ \\
\hline A-1 & $300 \times 300$ & $16 \mathrm{~B} 12$ & $200 \times 7$ & A6@50 & $280 \times 300$ & 10B22 & A8@200 & A6@50 \\
\hline A-2 & $300 \times 300$ & $16 \mathrm{~B} 12$ & $200 \times 7$ & A6@50 & $280 \times 300$ & 10B22 & A8@200 & A8@50 \\
\hline B-1 & $300 \times 300$ & $16 \mathrm{~B} 12$ & $200 \times 7$ & A6@50 & $280 \times 300$ & $10 \mathrm{~B} 22$ & A8@200 & A6@50 \\
\hline B-2 & $300 \times 300$ & $16 \mathrm{~B} 12$ & $200 \times 7$ & A6@50 & $280 \times 300$ & $10 \mathrm{~B} 22$ & A8@200 & A8@50 \\
\hline C-1 & $300 \times 300$ & $16 \mathrm{~B} 12$ & $200 \times 7$ & A6@50 & $280 \times 300$ & $10 \mathrm{~B} 22$ & A8@200 & A6@50 \\
\hline $\mathrm{C}-2$ & $300 \times 300$ & $16 \mathrm{~B} 12$ & $200 \times 7$ & A6@50 & $280 \times 300$ & $10 \mathrm{~B} 22$ & A8@200 & A8@50 \\
\hline
\end{tabular}

TABle 2: Properties of rebars and steel plate (unit: $\mathrm{N} / \mathrm{mm}^{2}$ ).

\begin{tabular}{lccc}
\hline Materials and specifications & Yield strength $f_{\mathrm{y}}^{0}$ & Ultimate strength $f_{\mathrm{u}}^{0}$ & Modulus of elasticity $E_{s}^{0}$ \\
\hline Steel plate & 239.6 & 336.0 & $2.10 \times 105$ \\
B22 & 353.8 & 568.3 & $2.11 \times 105$ \\
B12 & 380.2 & 549.8 & $2.09 \times 105$ \\
A8 & 310.2 & 495.7 & $2.08 \times 105$ \\
A6 & 330.8 & 512.6 & $2.06 \times 105$ \\
\hline
\end{tabular}

TABle 3: Properties of concrete (unit: N/mm²).

\begin{tabular}{lcccc}
\hline Strength grade of concrete & Cubic compressive strength $f_{\mathrm{cu}, \mathrm{k}}^{0}$ & Axial compressive strength $f_{\mathrm{c}}^{0}$ & Modulus of elasticity $E_{\mathrm{c}}^{0}$ \\
\hline C40 & 39.0 & 26.1 & $2.77 \times 10^{4}$ \\
\hline
\end{tabular}

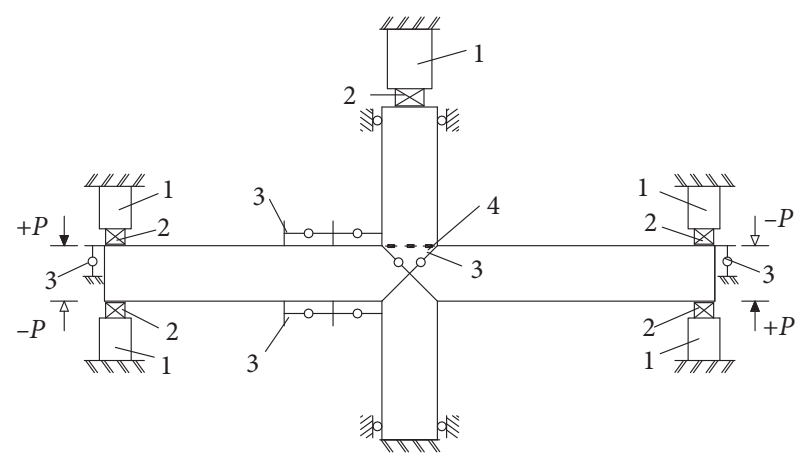

FIgURE 3: Low-cycle reversed loading device. (1) Jack, (2) load transducer, (3) displacement transducer, and (4) strain gauges.

loads are applied synchronously at the end of beam. The first and second cycles are loaded by the loading control, and the load values are $25 \%$ and $75 \%$ of the calculated yielding loads of beam sections, respectively; the stress of joints in the usage stage is simulated. Then, the load is controlled by displacement with control point at the end of the beam and cycled twice under each grade of displacement, stopping it when the load at the end of beam falls to $85 \%$ of the maximum loads. The specimen is considered to yield when the reinforcements in the beam yield. The loading program is shown in Figure 4.

The resistance strain gauges are pasted on the steel reinforced in longitudinal and transverse directions, hooping, beam-column longitudinal reinforcement, and concrete surface of diagonal direction. The displacement transducers are arranged at the beam end to calculate the rotation of plastic hinge. The displacement transducers are

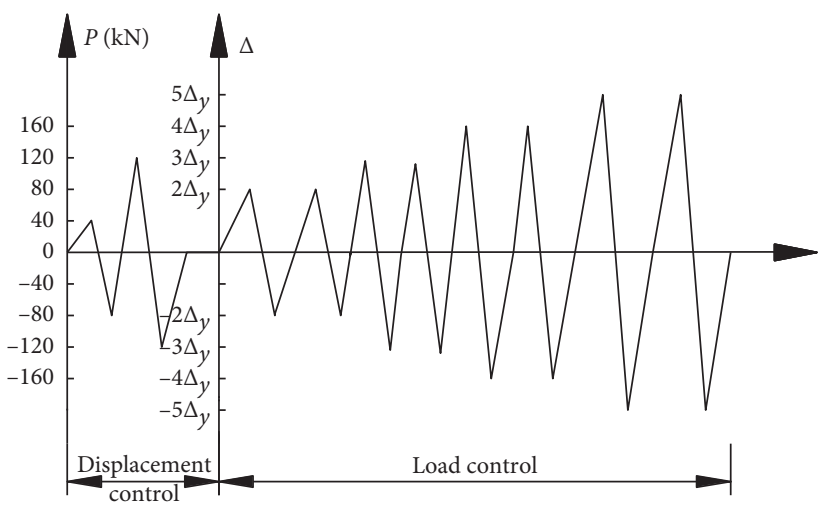

FIGURE 4: Low-cycle reversed loading program.

arranged in the diagonal direction to measure the shear deformation in core area. The "displacement transducer" is used to measure the shear deformation in the joint and vertical displacement of the beam end. The beam-end displacement transducers and pressure transducers are connected with $X-Y$ recorder to draw the load-displacement curve so as to control the whole loading process.

In the loading mode shown in Figure 3, the core of the node is stressed as shown in Figure 5. According to the joint stress balance condition and the shear stress mutual law, the relationship between the horizontal shear force design value $V_{\mathrm{j}}$ and the beam end load in the core area of the joint can be expressed by the following formula [25]:

$$
V_{\mathrm{j}}=\frac{\left(H_{\mathrm{c}}-h_{\mathrm{b}}-h_{\mathrm{b}}^{\prime}\right)\left(H_{\mathrm{b}}-h_{\mathrm{c}}^{\prime}\right)}{\left(H_{\mathrm{c}}-h_{\mathrm{b}}\right) h_{\mathrm{b}}^{\prime}} P
$$




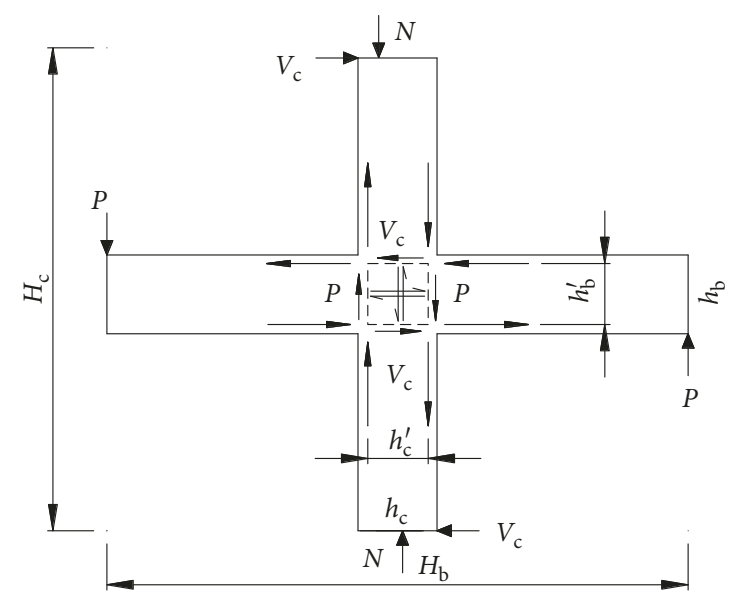

FIgURE 5: Free body diagram of the interior joint.

where $H_{\mathrm{c}}$ is the height of the column, $H_{\mathrm{b}}$ is the length of the beam, $h_{\mathrm{b}}$ is the height of the beam section, $h_{\mathrm{c}}$ is the height of the column section, $h_{\mathrm{b}}^{\prime}$ is the effective height of the beam section and $h_{\mathrm{c}}^{\prime}$ is the effective height of the column section, and $P$ is the beam end load.

3.1.3. Whole Stress Process of Specimens and Failure Mechanism. The experiment results show that all the specimens are subject to shear failure in the joint core area and go through three stages of the whole process from loading to failure: noncracking, cracking, and failure.

(1) Noncracking Stage. Under small loads, both the vertical displacement of free end of the beam and the shear deformation of joint core area are very small, and the load and deformation are straight and linearly related. When the load reaches $25 \mathrm{kN}$, the first vertical crack appears on the beam intersecting with the column, but there is no crack in core area. Three groups of joint specimens are basically the same in this stage.

(2) Cracking Stage. When the load rises to about $60 \mathrm{kN}$, the first diagonal crack appears in the middle of joint core area, with a width of about $0.5 \mathrm{~mm}$. At this time, the strain of steel tube and concrete in the joint area is basically consistent; both vertical displacement of beam end and shear deformation of core area are very small; the transverse deformation of hooping and steel tube in the joint area is also very small; the joint shear-force is mainly borne by concrete and steel reinforced. The cracking loads of joints with different holes are approximately the same in joint area, and the cracking load is about $40 \%$ of the failure load. When the initial crack occurs in the joint area, the crack on the beam increases less. When the load increases to $120 \mathrm{kN}$, the longitudinal reinforcement at the beam end intersecting with the column yields; the displacement at this time is $\Delta y$. The first crack in the core area widens further; at the same time, many diagonal cracks generate and form a cluster of cross-diagonal cracks. At this time, the performance of three groups of specimens is roughly the same.
(3) Failure Stage. After the beam longitudinal reinforcement intersecting with column yields, the displacement control is adopted for loading. When the displacement at the free end of beam increases to $2 \Delta y$, a main diagonal crack is formed in the core area, which basically threads through along the diagonal direction. The core area is basically in a "full crack" state, and the stiffness of joints decreases significantly. At this time, the performance of three groups of specimens is different. Group A specimens: when the beam-end displacement is close to $2 \Delta y$, the concrete on the side of joint area has begun to peel off. When the displacement reaches $2 \Delta y$, the hooping yields. Groups B and C specimens: when the beam-end displacement increases to $2 \Delta y$, the hooping in the core area still does not fully yield. When the displacement reaches $3 \Delta y$, all hooping in the joint area yields, and steel reinforced also yields, but the bearing capacity can still increase about (10-20)\%. When the displacement of Group A specimens increases to $3 \Delta y$, and that of Groups B and C specimens to $4 \Delta y$, the concrete on the side of joint area seriously cracks, the hooping in the joint area is exposed, the load declines to less than $85 \%$ of the maximum loads, and the specimens are damaged.

3.2. Numerical Finite Element Simulation. In order to investigate the effectiveness of the numerical model, a numerical finite element analysis is carried out for the framework joints of SRCFCST low-cyclic load experiment specimens in reference. Based on the experiment data of material properties and the constitutive model aforementioned, the stress-strain curves of concrete under uniaxial compression and tension are shown in Figure 6, and the compressive damage coefficient curves of concrete are shown in Figure 7 . In the calculation, a fixed axial force $N$ $(1000 \mathrm{kN})$ is applied at the top of the column, and then a repetitive concentrated load $P$ or a repetitive vertical displacement $\Delta$ is applied at the end of the beam. The loaddisplacement hysteretic loops can reflect the relationship between load and strain of the joint under cyclic loads, as well as the energy dissipation capacity. Six specimens were established in ABAQUS and divided into the following three groups: nonapertured group (group A), specimen group (group B), and macroporous group (group C). These groups are differentiated by the type of perforation cavity on the end of steel tubes. The difference between the three groups only was the form of hole on the end of the steel tube. In calculation, firstly, fixed axial force $N(1000 \mathrm{kN})$ was applied to the top of the column, and then a pair of reciprocating concentrated loads $P$ or reciprocating vertical displacements $\Delta$ of which equal value but opposite direction was applied to both ends of the beam. From the load-displacement hysteretic loop curves of the beam end, the relationship between the load and strain of the joint under the reciprocating load as well as the capacity of energy dissipation could be reflected.

Figure 8 shows the comparison on load-displacement hysteretic loops between FEA results and experiment results, which implies that the finite element calculation results of each group of specimens basically coincide with the 


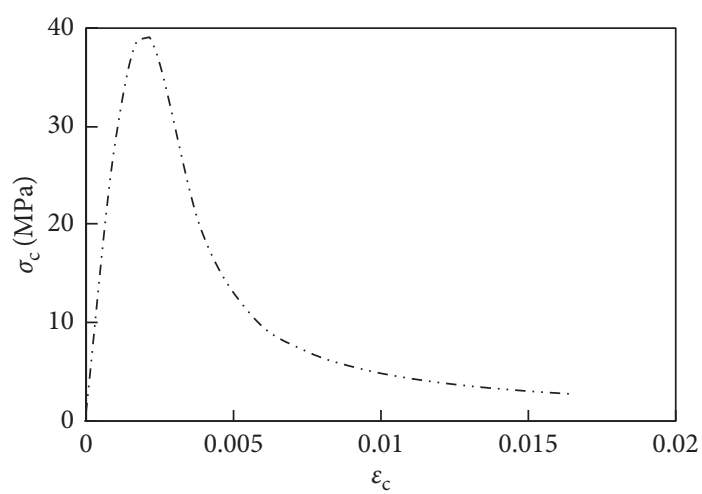

(a)

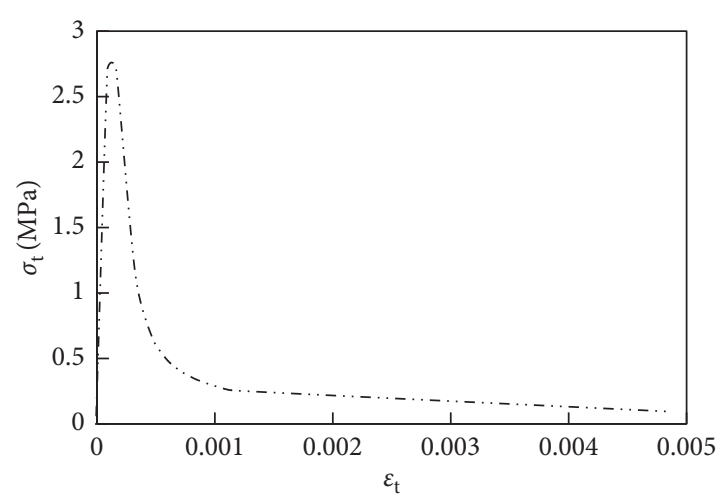

(b)

FIgure 6: Concrete uniaxial constitutive curve. (a) Compression constitutive relation curves. (b) Tensile constitutive relation curves.

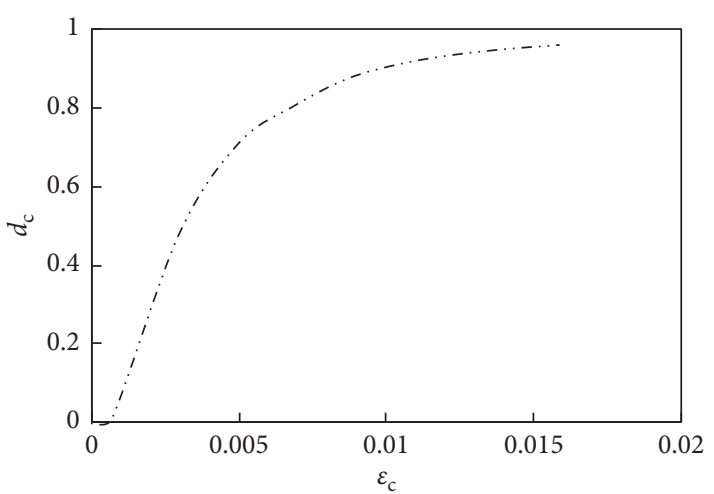

Figure 7: Relation curve of compression damage coefficient of concrete.

experiment results. In general, the finite element hysteretic curve is fuller than the test curve, which is mainly caused by that it is difficult to accurately consider the crack opening and closing of concrete and the bond-slip effect between steel bar, section steel, and concrete in the finite element calculation [26]. According to the results of finite element calculation of each group, the hysteretic curves of reinforcement-perforated specimens are fuller than those of nonperforated specimens and large-hole specimens, indicating that reinforcement-perforated specimens have the best deformation, ductility, and energy dissipation properties, which accords with the experiment results [19].

Figure 9 shows the comparison on load-displacement skeleton curves between FEA results and experiment results, which indicates that the results of finite element calculation coincide well with the experiment results. The experiment value of ultimate bearing capacity of Groups A and B specimens is slightly larger than results of finite element calculation except that the experiment value of two specimens in Group C are quite different.

In summary, specimen in Group B has the best effect. The main reason is that a reinforced concrete shear pin is formatted through the small hole, increasing the concrete bonding effect, and the concrete in and out of the tube can work together through the small hole improving the integrity of concrete in core area.

\section{Theoretical Analysis of Shear Bearing Capacity of Joints}

4.1. Shear Mechanism of Joints. Figure 10 shows the general composition and equivalence of the SRCFCST column section. Different from the SRC columns with H-shaped steel, cross-shaped steel, or rectangular steel tube, CSTs are distributed uniformly around the section without definite flange and web. In addition, the mechanical properties of concrete inside and outside tube are different due to varied constraints. In order to understand the shear bearing mechanism of joints easily, in this paper, CST is equivalent to rectangular steel tube; the corresponding inner-core concrete inside and outside tube is also in the corresponding rectangular section range.

Figure 11 indicates the equivalent principle that the area of flange and the web are equal. It should be noted that the flange and web should adopt different thicknesses in the rectangular steel tube section in order to satisfy the principle because the height of the two parts are not identical.

Because the steel tube involved in the shear is mainly the part at the middle height of joint core area, in the equivalence to CST, the flange area and web area of the rectangular steel tube are equal, and the height of the rectangular steel tube is equal to the diameter $D$ of the steel tube. The area of core concrete is equal to the area of concrete inside the steel tube. Based on the equivalence principle above, the equivalent rectangular section width of concrete inside and outside tube and the thickness of flange and web of equivalent rectangular section steel tube can be obtained. The thickness-diameter ratio of the steel tube is expressed as $\xi=t_{w} / D$, where $t_{w}$ is the wall thickness of CST, and then

$$
\begin{aligned}
b_{\mathrm{cor}, \mathrm{j}} & =\frac{\pi D^{2}}{4 h_{\mathrm{c}}}, \\
b_{\mathrm{out}, \mathrm{j}} & =b_{\mathrm{c}}-\frac{\pi D^{2}}{4 h_{\mathrm{c}}}, \\
t_{\mathrm{fla}} & =\xi(1-\xi) h_{\mathrm{c}}, \\
t_{\mathrm{web}} & =\frac{\pi \xi(1-\xi) D^{2}}{4\left[D-2 \xi(1-\xi) h_{\mathrm{c}}\right]},
\end{aligned}
$$




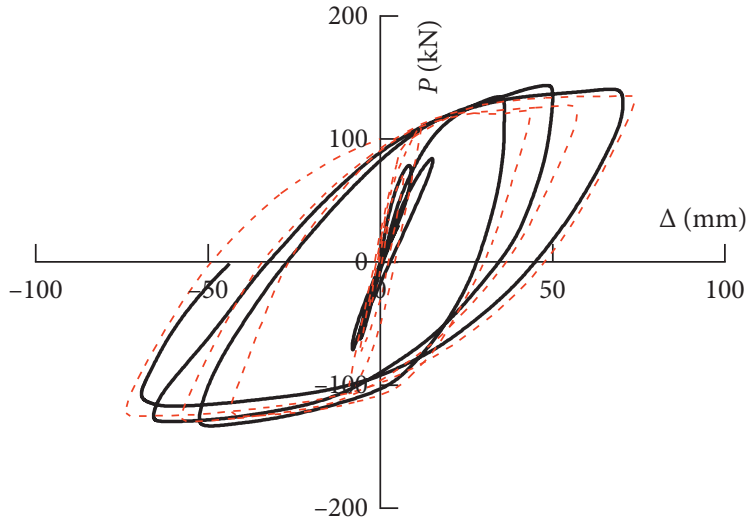

- Experiment

Numerical simulation

(a)

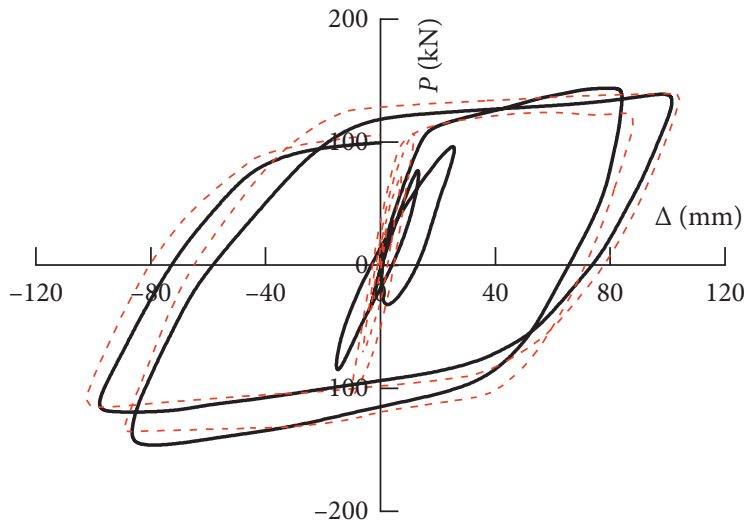

Experiment

Numerical simulation

(c)

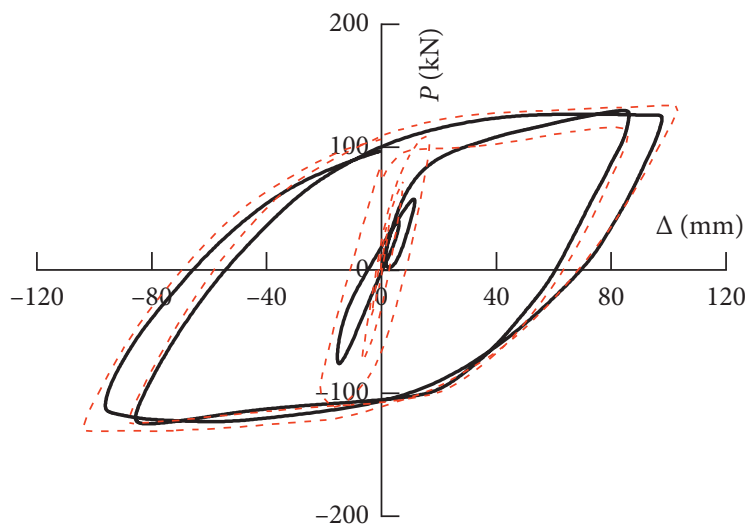

- Experiment

- . - Numerical simulation

(e)

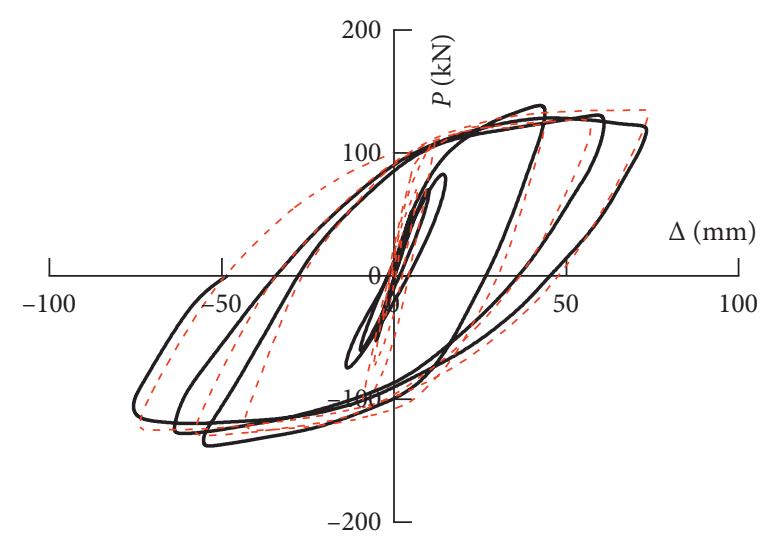

Experiment

Numerical simulation

(b)

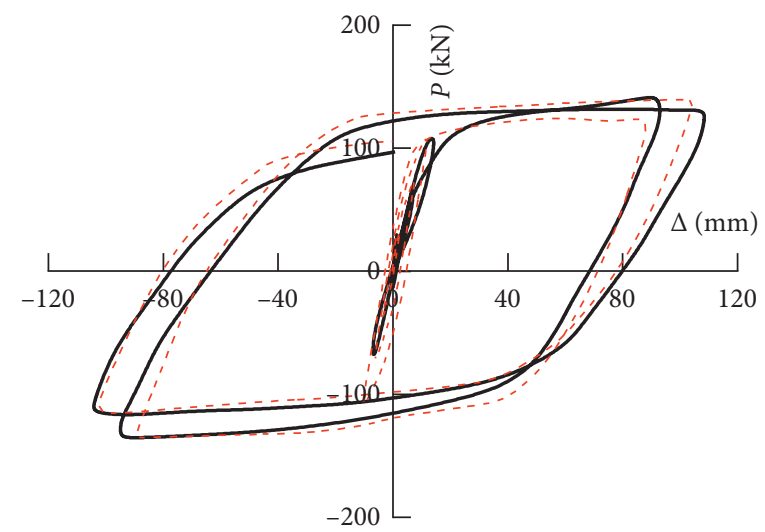

Experiment

Numerical simulation

(d)

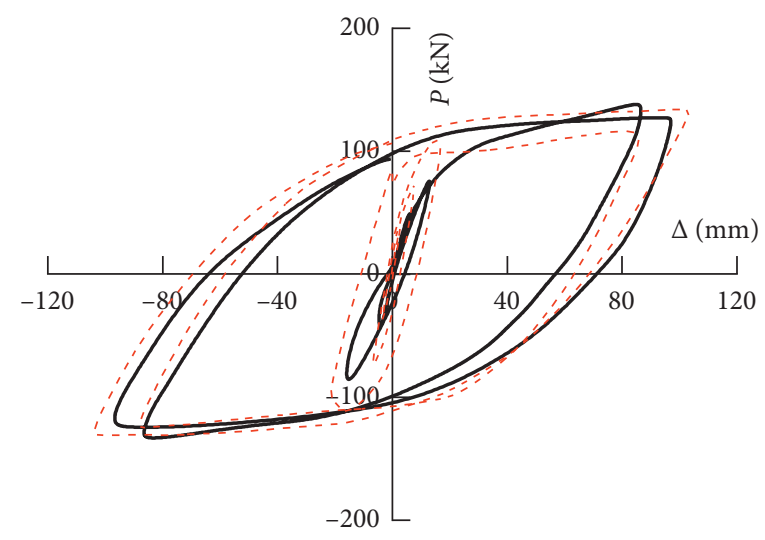

- Experiment

- . - Numerical simulation

(f)

FIGURE 8: Comparison on load-displacement hysteretic loops between FEA results and experiment results. (a) Specimen A1. (b) Specimen A2. (c) Specimen B1. (d) Specimen B2. (e) Specimen C1. (f) Specimen C2.

where $b_{\text {cor,j }}$ is the equivalent rectangular section width of concrete inside the tube, $b_{\text {out, }}$ is the equivalent rectangular section width of concrete outside the tube, $t_{\text {fla }}$ is the flange thickness of the equivalent rectangular section steel tube, $t_{\text {web }}$ is the web thickness of the equivalent rectangular section steel tube, $b_{c}$ is the width of the column section, and $h_{c}$ is the height of the column section. 


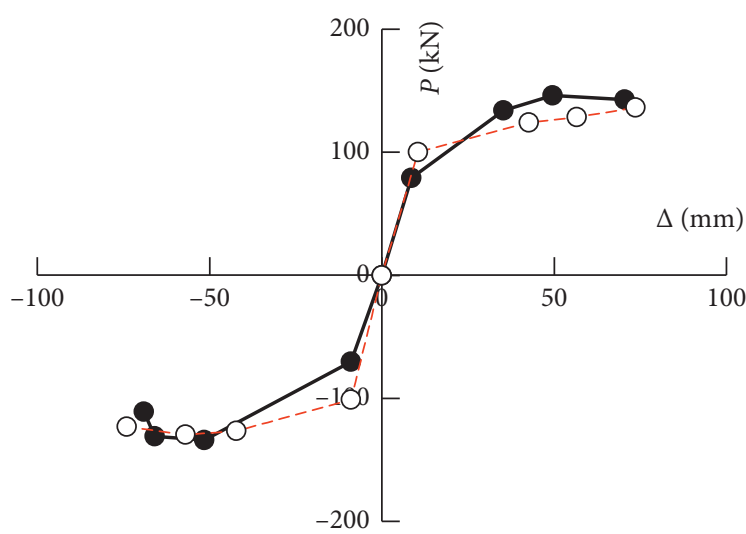

Experiment

-O- Numerical simulation

(a)

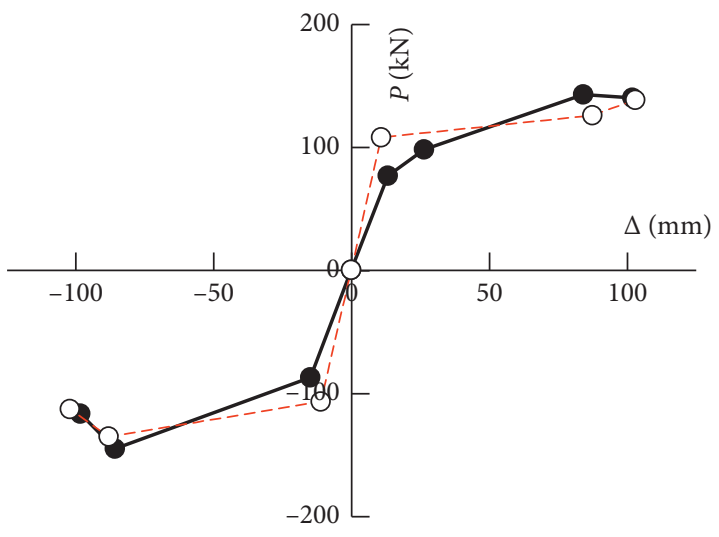

Experiment

-O- Numerical simulation

(c)

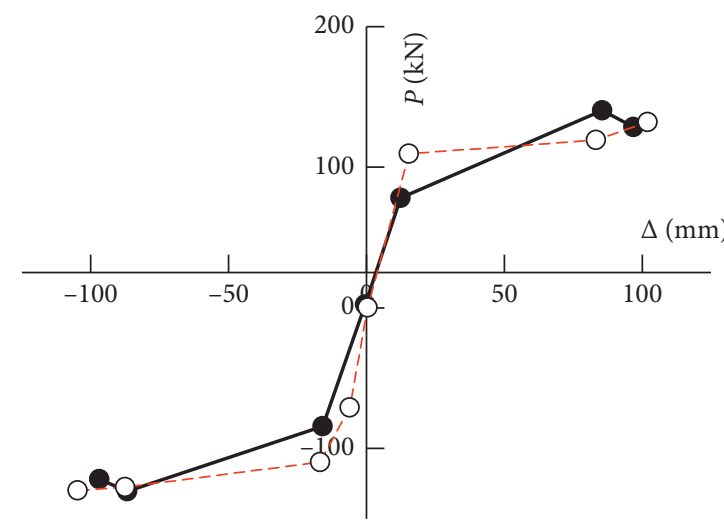

Experiment

-O- Numerical simulation

(e)

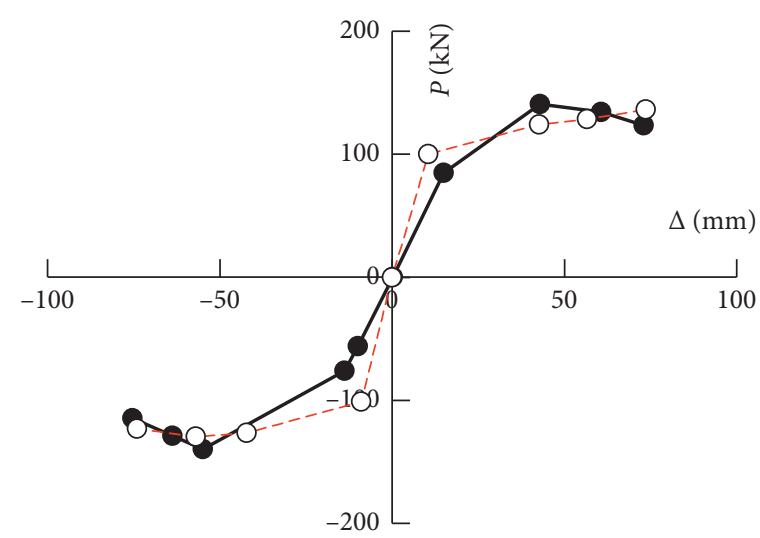

Experiment

Numerical simulation

(b)

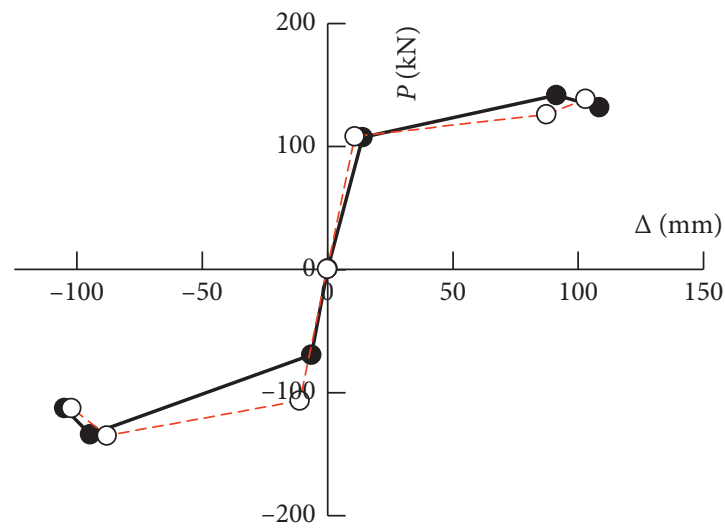

Experiment

Numerical simulation

(d)

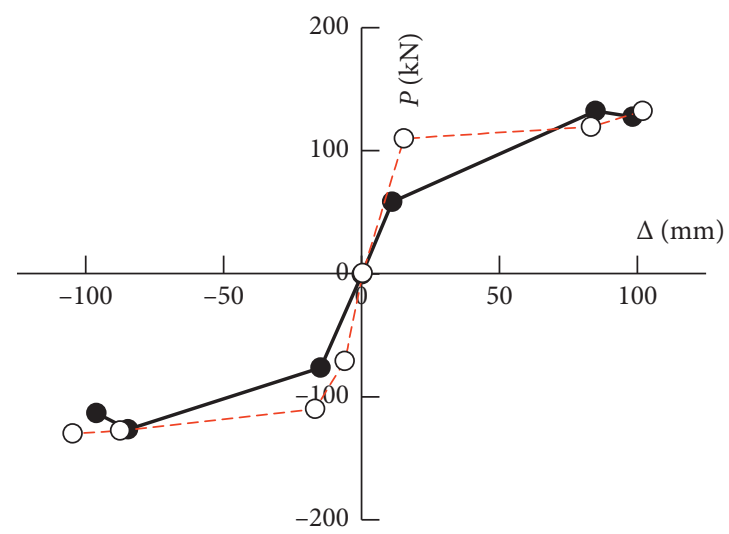

Experiment

-O- Numerical simulation

(f)

Figure 9: Comparison on load-displacement skeleton curves between FEA results and experiment results. (a) Specimen A1. (b) Specimen A2. (c) Specimen B1. (d) Specimen B2. (e) Specimen C1. (f) Specimen C2.

4.2. Calculation of Shear Bearing Capacity of Joints. At present, there is no special method for calculating the shear bearing capacity of composite joints of SRCFCST column with reinforced concrete frame beam. Based on the relevant experimental and numerical analysis results, it can be seen from the equivalence for column section by methods 


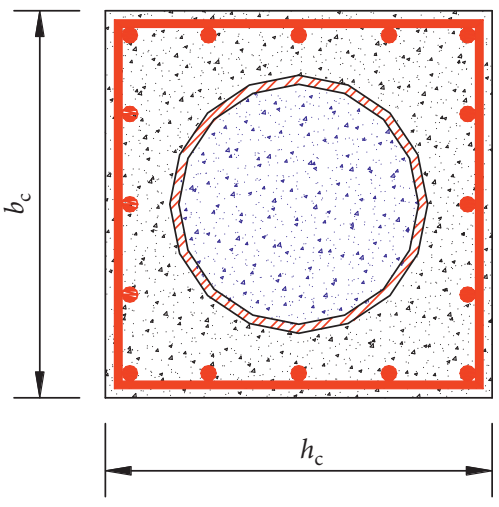

(a)

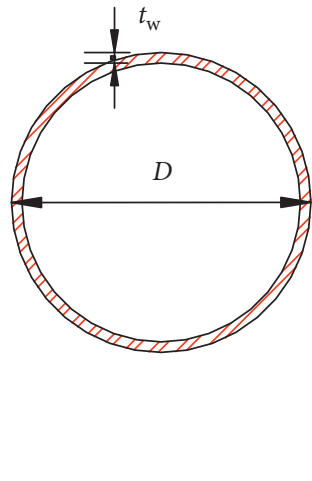

(b)

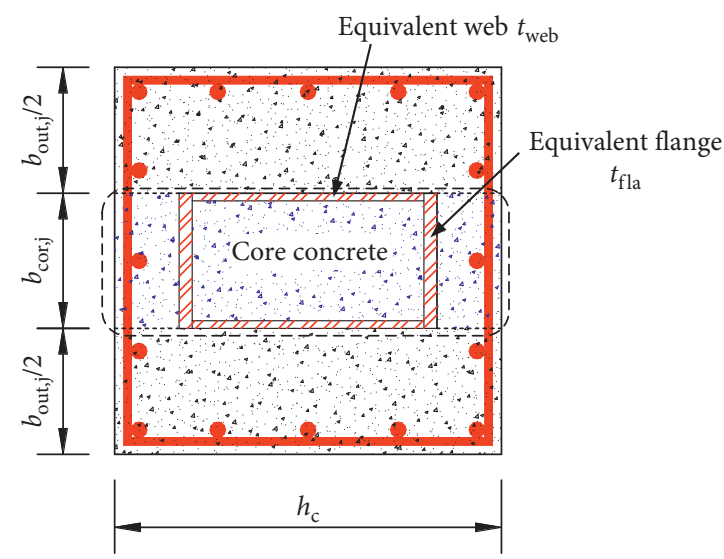

(c)

FIGURE 10: Section composition and equivalence of SRCFCST column section. (a) SRCFCST column section. (b) Circular steel tube. (c) Equivalence of SRCFCST column section.
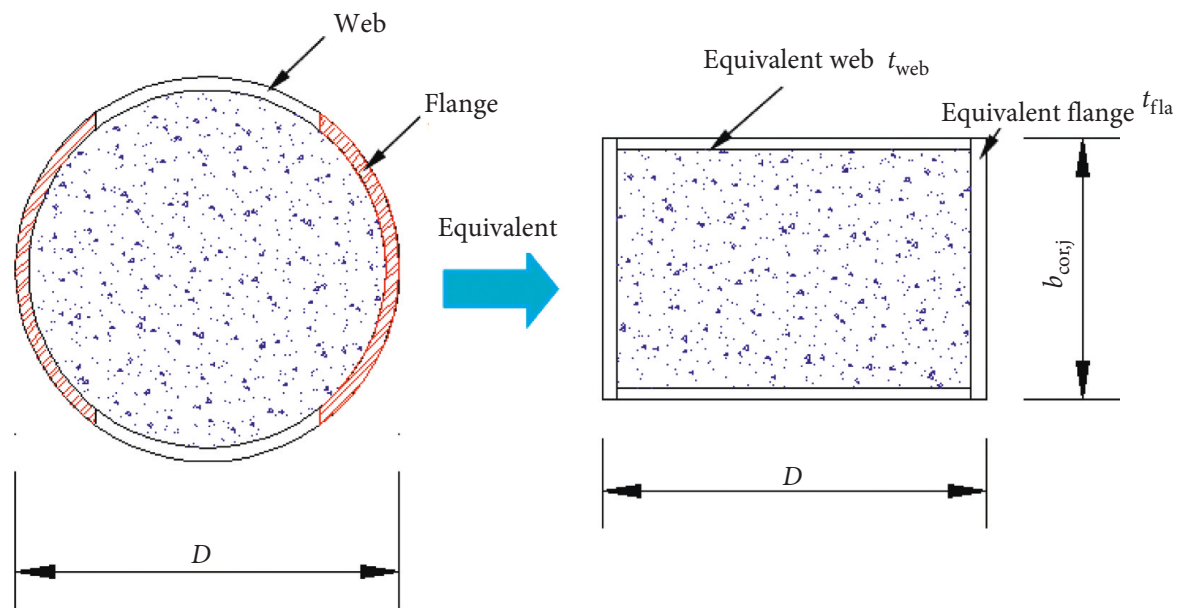

FIGURE 11: Inner concrete of tube and steel tube equivalent diagram.

mentioned above that there are many similarities in shear mechanism between framework joints of SRCFCST and that of rectangular or square SRC framework joints [26-28]. In this paper, the shear bearing capacity of SRCFCST column is divided into four parts by referring to the calculation method for general SRC column-beam composite joints proposed by existing codes, regulations, and relevant scholars, i.e., (1) the shear bearing capacity provided by concrete outside the tube of joint area, $V_{\text {out }}$; (2) the shear bearing capacity provided by concrete inside the tube of joint area, $V_{\text {cor }}$; (3) the shear bearing capacity provided by hooping of joint area, $V_{\text {sv }}$; and (4) the shear bearing capacity provided by the steel section web of joint area, $V_{\mathrm{w}}$. By superimposing the four parts above, the basic formula of the horizontal shear bearing capacity $V_{\mathrm{j}}$ in joint core-area can be obtained as follows:

$$
V_{j}=V_{\text {out }}+V_{\text {cor }}+V_{\text {sv }}+V_{\text {w }}
$$

According to the SRCFCST column section equivalence and analysis of shear bearing capacity mechanism, the shear bearing capacity is provided by each part of joint area.
4.2.1. Shear Bearing Capacity Provided by Concrete Outside Tube. Due to the complex crack and conquassation behavior of concrete in the ultimate state, it is difficult to accurately calculate the shear bearing capacity it provided; and in the case of composite forces, the banded concrete inclined bar will form at joints [27]. With this regard, the shear bearing capacity provided by the concrete in joint area is calculated by the inclined bar theory. The shear mechanism of the concrete outside the tube in joint core area is shown in Figure 12(a). Because it is not constrained by the steel tube, its stress mechanism is similar to that of the joint concrete in [26]. The formula of computing the shear bearing capacity $V_{\text {out }}$ provided by concrete outside the tube is as follows:

$$
\begin{aligned}
& V_{\text {out }}=0.4 B_{\text {out }} b_{\text {out }, \mathrm{j}} f_{c}, \\
& B_{\text {out }}=0.3\left(h_{b}^{2}+h_{c}^{2}\right)^{1 / 2},
\end{aligned}
$$

where $f_{\mathrm{c}}$ is the design compressive strength of concrete, $h_{\mathrm{b}}$ is the beam height in joint core area, and $B_{\text {out }}$ is the height of the concrete inclined bar outside the tube. 


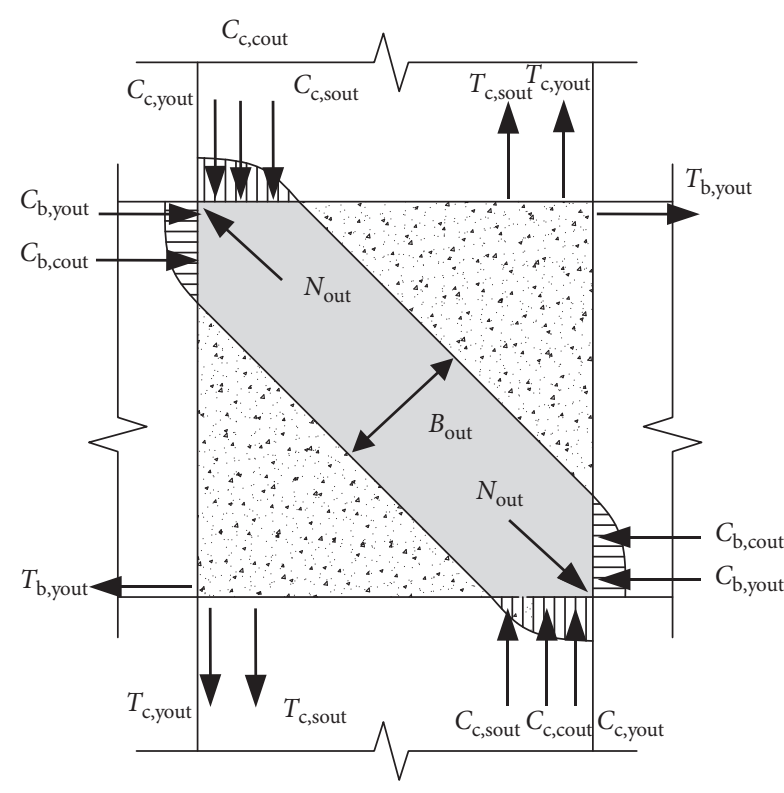

(a)

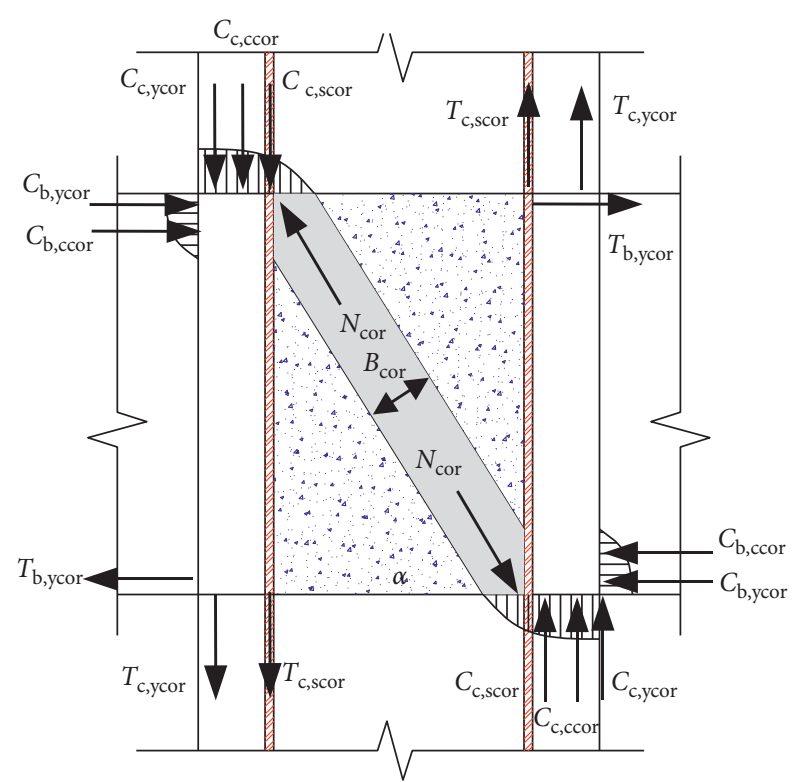

(b)

FIgURE 12: Shear mechanism of the concrete inclined column. (a) Concrete outside the tube. (b) Concrete inside the tube.

4.2.2. Shear Bearing Capacity Provided by Concrete Inside

Tube. As constrained by the steel tube, the compressive strength of concrete in joint core area is higher than that of general concrete. The shear mechanism is shown in Figure 12(b). Referring to SRC framework joints [28, 29], the shear bearing capacity $V_{\text {cor }}$ provided by concrete inside tube can still be calculated by inclined bar theory. The calculation formula is as follows:

$$
V_{\text {cor }}=0.5 B_{\text {cor }} b_{\text {cor, } \mathrm{j}} f_{\text {sc }} \cos \alpha,
$$

where $B_{\text {cor }}$ is the height of the concrete inclined bar in the tube, $\alpha$ is the obliquity of the bar, and $f_{\mathrm{sc}}$ is the compressive strength of the confined concrete in the tube.

The formulas for calculating the obliquity $\alpha$ of bar and the height $B_{\text {cor }}$ of the concrete inclined bar in tubes are as follows [28]:

$$
\begin{aligned}
u & =\frac{N}{f_{\mathrm{c}} A_{\mathrm{c}}+f_{\mathrm{a}} A_{\mathrm{s}}}, \\
\alpha & =\arctan \left[\frac{0.75}{(0.75-0.85 \mu)} \cdot \frac{h_{\mathrm{b}}}{\left(D-2 t_{\mathrm{fla}}\right)}\right], \\
\alpha_{1}= & \arctan \left[\frac{h_{\mathrm{b}}}{(1+3.4 \mu)\left(D-2 t_{\mathrm{fla}}\right)}\right], \\
B_{\mathrm{cor}}= & \frac{1}{4}\left[h_{\mathrm{b}}^{2}+(1+3.4 \mu)\left(D-2 t_{\mathrm{fla}}\right)^{2}\right]^{1 / 2}, \\
& \cos \left(\frac{\pi}{2}-\alpha-\alpha_{1}\right),
\end{aligned}
$$

where $u$ is the axial pressure coefficient, $N$ is the design value of column axial force, $f_{\mathrm{a}}$ is the design value of section steel compressive strength, $A_{\mathrm{c}}$ is the area of the concrete section, and $A_{\mathrm{s}}$ is the area of the steel tube section.
The compressive strength $f_{\mathrm{sc}}$ of confined concrete in the tube can be calculated according to GB 50936-2014 Technical code for Concrete-Filled Steel Tubular Structures [30]:

$$
\begin{aligned}
& f_{\mathrm{sc}}=\left(1.12+B \theta_{\mathrm{sc}}+C \theta_{\mathrm{sc}}^{2}\right) f_{\mathrm{c}}, \\
& \theta_{\mathrm{sc}}=\frac{f_{\mathrm{a}} A_{\mathrm{s}}}{f_{\mathrm{c}} A_{\mathrm{c}}},
\end{aligned}
$$

where $\theta_{\text {sc }}$ is the reinforcement-sheath coefficient and $B$ and $C$ are coefficients and calculated according to the following formulas, respectively:

$$
\begin{aligned}
& B=\frac{0.974+0.176 f_{a}}{213}, \\
& C=\frac{0.031-0.104 f_{c}}{144} .
\end{aligned}
$$

4.2.3. Shear Bearing Capacity Provided by Stirrup. On the one hand, the contribution of hooping in joint core area to shear force lies in that it forms the truss working mechanism with beam-column longitudinal reinforcement and concrete inclined bar [28]. On the other hand, the hooping will restrain the concrete in core area, depress the crack propagation and shear deformation in core area, and thus enhance the shear capacity of the joint core area [29]. The shear bearing capacity $V_{\text {sv }}$ provided by hooping can be calculated according to the following formula:

$$
V_{\mathrm{sv}}=\frac{\left(h_{0}-a_{\mathrm{s}}^{\prime}\right)}{s} f_{\mathrm{yv}} A_{\mathrm{sv}}
$$


TABLE 4: Comparison of the test value and finite element of shear bearing capacity.

\begin{tabular}{lccc}
\hline Specimen & Experimental value $V_{\mathrm{j}, \mathrm{E}}(\mathrm{kN})$ & FEM $V_{\mathrm{j}, \mathrm{F}}(\mathrm{kN})$ & $V_{\mathrm{j}, \mathrm{F}} / V_{\mathrm{j}, \mathrm{E}}$ \\
\hline $\mathrm{A} 1$ & 1066.5 & 1024.8 & 0.96 \\
$\mathrm{~A} 2$ & 1073.6 & 1024.8 & 0.96 \\
$\mathrm{~B} 1$ & 1172.1 & 1057.5 & 0.90 \\
$\mathrm{~B} 2$ & 1119.2 & 1057.5 & 0.95 \\
$\mathrm{C} 1$ & 1028.5 & 1059.8 & 1.03 \\
C2 & 1119.2 & 1059.8 & 0.95 \\
\hline
\end{tabular}

TABLE 5: Size, reinforcement, and structure of specimens.

\begin{tabular}{|c|c|c|c|c|c|c|c|c|}
\hline \multirow[b]{2}{*}{$\begin{array}{l}\text { Specimen } \\
\text { no. }\end{array}$} & \multicolumn{4}{|c|}{ Column } & \multicolumn{4}{|c|}{ Beam } \\
\hline & $\begin{array}{l}B \times h \\
(\mathrm{~mm})\end{array}$ & $\begin{array}{l}\text { Longitudinal } \\
\text { reinforcement }\end{array}$ & $\begin{array}{l}\text { Steel reinforced } \\
D \times t(\mathrm{~mm})\end{array}$ & Hooping & $\begin{array}{l}b \times h \\
(\mathrm{~mm})\end{array}$ & $\begin{array}{c}\text { Longitudinal } \\
\text { reinforcement }\end{array}$ & Hooping & $\begin{array}{l}\text { Hooping in joint } \\
\text { core area }\end{array}$ \\
\hline SRCTJ1 & $500 \times 500$ & $16 \mathrm{~B} 12$ & $350 \times 8$ & A8@100 & $400 \times 600$ & $20 \mathrm{~B} 30$ & A8@150 & A8@100 \\
\hline SRCTJ2 & $600 \times 600$ & $16 \mathrm{~B} 14$ & $450 \times 8$ & A8@100 & $500 \times 700$ & $24 \mathrm{~B} 30$ & A8@150 & A8@100 \\
\hline SRCTJ3 & $700 \times 700$ & $20 \mathrm{~B} 16$ & $550 \times 8$ & $\begin{array}{c}\text { A10@ } \\
100\end{array}$ & $600 \times 800$ & $24 \mathrm{~B} 32$ & $\begin{array}{c}\text { A10@ } \\
150\end{array}$ & A10@100 \\
\hline SRCTJ4 & $800 \times 800$ & $20 \mathrm{~B} 18$ & $650 \times 8$ & $\begin{array}{c}\text { A10@ } \\
100 \\
\end{array}$ & $700 \times 900$ & $24 \mathrm{~B} 40$ & $\begin{array}{c}\text { A10@ } \\
150 \\
\end{array}$ & A10@100 \\
\hline
\end{tabular}

where $h_{0}-a_{\mathrm{s}}^{\prime}$ is the height of the column section after removing the thickness of upper and lower protective layers, $s$ is the hooping spacing of core area, $f_{\mathrm{yv}}$ is the tensile strength of hooping, and $A_{\mathrm{sv}}$ is the total area of hooping in the same section of core area.

4.2.4. Shear Bearing Capacity Provided by Steel Tube. The test reveals that the steel tube is always pulled in the circumferential direction during the whole process of shear in joint core area and yielded in the case of failure; however, the steel tube involved in the shear is mainly located in the part at the middle height of joint core area. In consideration of the restraint effects of the steel tube on concrete in the tube and the equivalent condition of SRCFCST column section steel tube, the calculation method for shear bearing capacity can be provided by referring to the SRC framework joints of ultrahigh-strength concrete and general SRC framework joint web $[26,28]$. On account of the influence of the holing of steel tube section at the joint, the shear bearing capacity $V_{\mathrm{w}}$ provided by the steel tube can be calculated according to the following formula:

$$
V_{\mathrm{w}}=1.1\left(1-\eta^{3}\right)\left(D-2 t_{\mathrm{fla}}\right) f_{\mathrm{a}} t_{\mathrm{web}}
$$

where $\eta$ is the hole rate of the steel tube section at the joint.

\section{Analysis of Joint Shear Bearing Capacity}

Table 4 shows the comparison on test values, finite element calculation values, and theoretical calculation values of shear bearing capacity. The table shows that the ratio of finite element calculation value to test value on shear bearing capacity is between 0.90 and 1.03 and both are in good agreement, which indicates that the numerical model established for SRCFCST column-reinforced concrete frame beam composite joints is basically reasonable.
In order to verify the correctness of the theoretical formula proposed in this paper, the paper also designs four internal steel tube steel-reinforced concrete column frame joints according to the principle of "weak node and strong component." The strength grade of concrete is C40, the longitudinal reinforcement is HRB335 reinforcing bar, the hooping is HPB235 reinforcing bar; the steel tube in column is roll welded by Q235 steel, the column height is $3.6 \mathrm{~m}$, the beam length is $5.3 \mathrm{~m}$; and other main parameters are shown in Table 5. Figure 13 shows the design diagram of SRCTJ1. Compared with the six specimens in Groups A-C, the newly designed joints have larger dimensions, and thus they can be applied to structure design directly.

The numerical model of framework joints of SRCFCST and formulas above for calculating shear bearing capacity are utilized to calculate the shear bearing capacity of test joints. Figure 14 shows load-displacement and hysteretic loops skeleton curves of newly designed joints of SRCFCST. Table 6 shows the comparison on test values, finite element calculation values, and theoretical calculation values of shear bearing capacity.

According to the above theoretical formula, the ratio of the calculated value to FEM is between 0.94 and 1.05 , which also indicates that the theoretical formulas have favorable calculation accuracy and are effective and feasible for calculation of shear bearing capacity of the SRCFCST column and reinforced concrete frame beam composite joints.

It needs be noted that the calculated values of finite element method and the theoretical formula given in Table 6 are obtained by the measured strength of concrete and steel; in engineering design, however, it is suggested that the calculation should be based on the design strength of material so as to reserve sufficient safety reserve for actual structure [31]. 

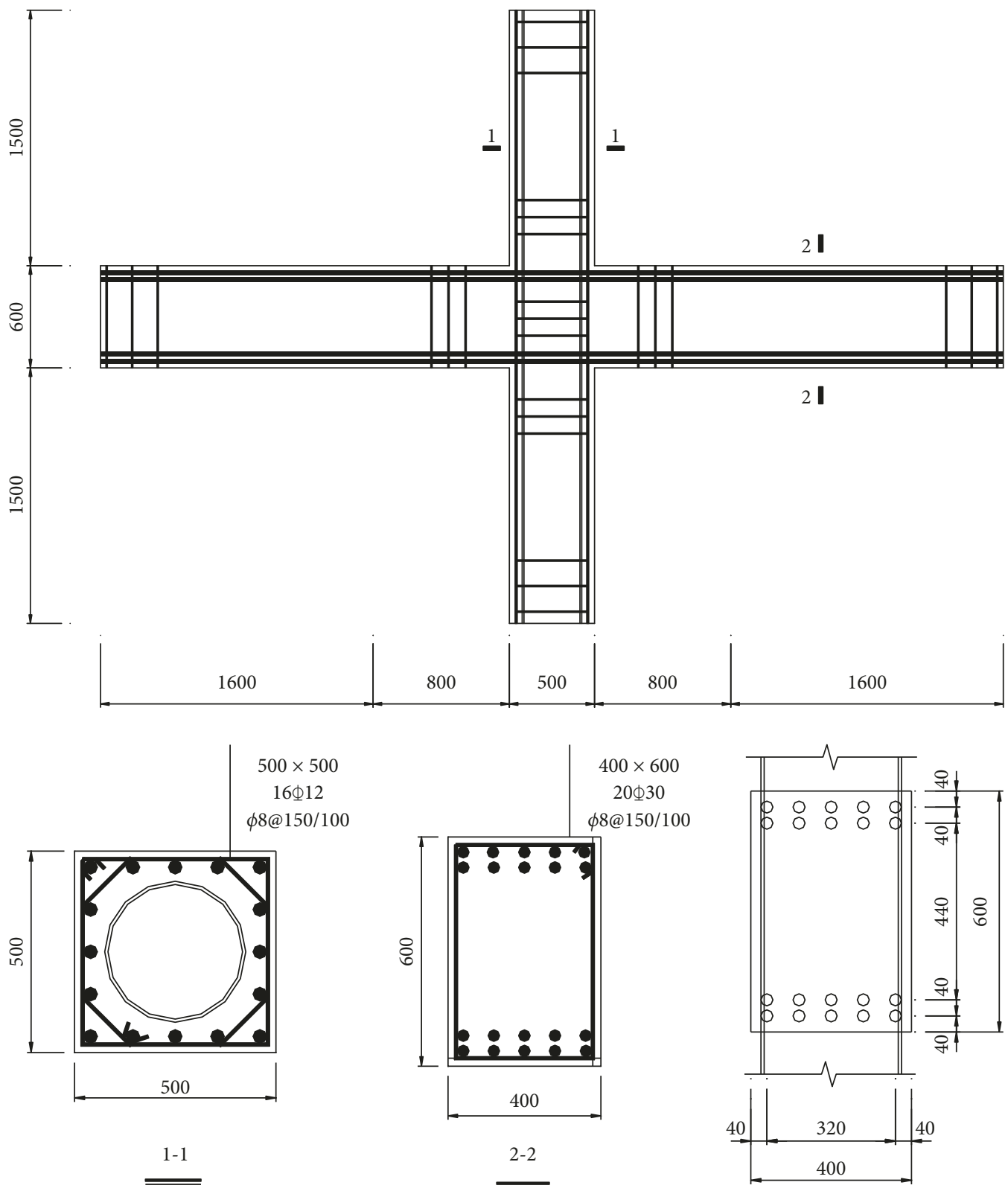

FIGURE 13: Design diagram of SRCTJ1.

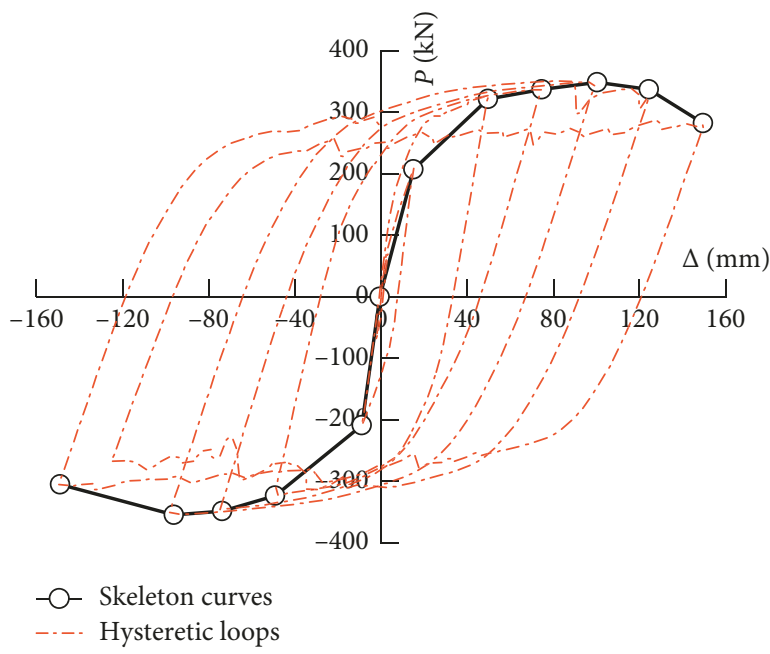

(a)

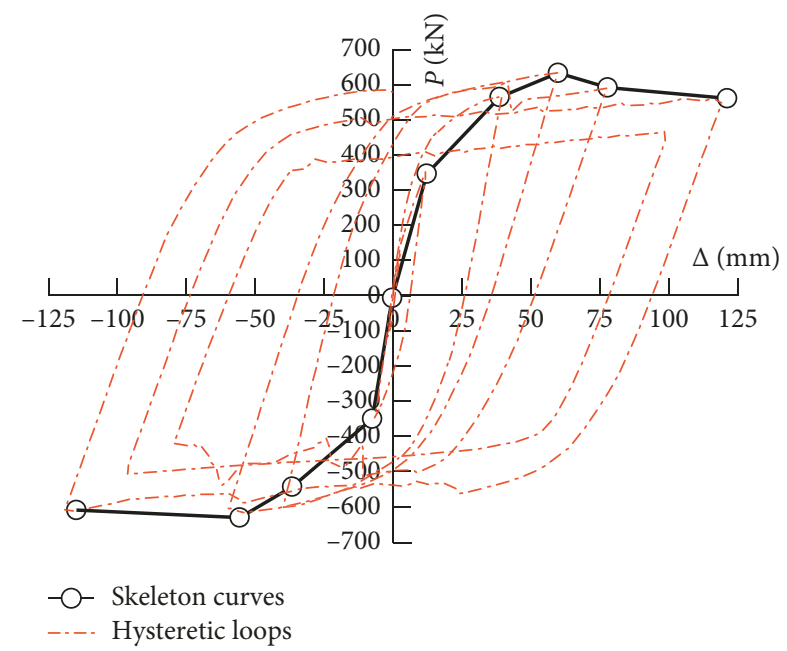

(b)

FIgUre 14: Continued. 


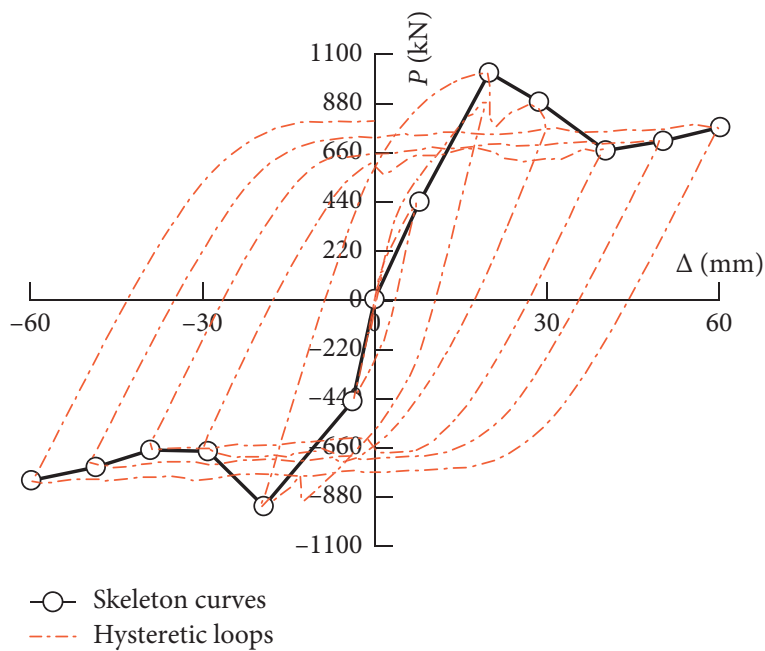

(c)

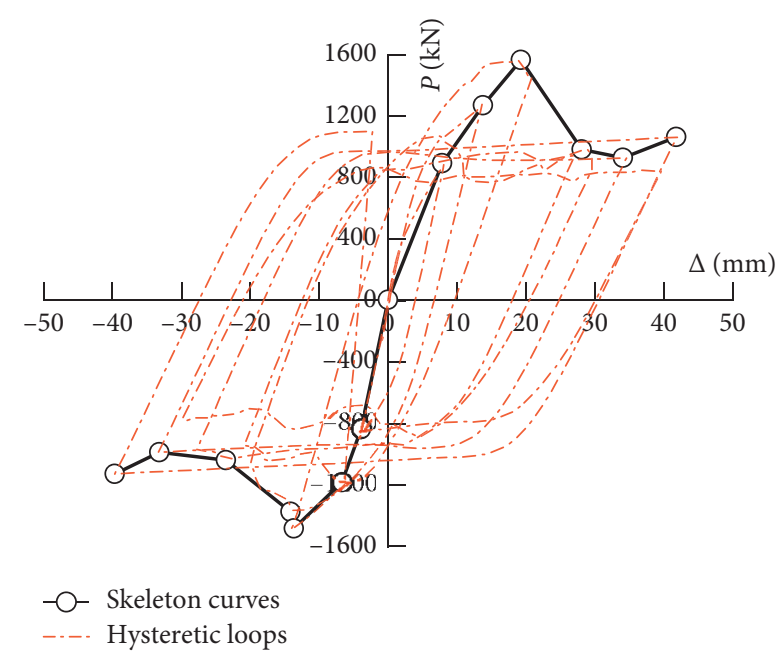

(d)

FIGURE 14: Load-displacement and hysteretic loops skeleton curves of newly designed joints of SRCFCST. (a) SRCTJ1. (b) SRCTJ2. (c) SRCTJ3. (d) SRCTJ4.

TABLE 6: Comparison of finite element and theoretical calculations of shear bearing capacity.

\begin{tabular}{lccc}
\hline Specimen & FEM $V_{\mathrm{j}}^{\mathrm{F}}(\mathrm{kN})$ & Theoretical calculation $V_{\mathrm{j}}^{\mathrm{c}}(\mathrm{kN})$ & 1040.88 \\
\hline A1/A2 & 1024.8 & 1040.39 & 1.02 \\
B1/B2 & 1057.5 & 1001.55 & 0.98 \\
C1/C2 & 1059.8 & 2928.08 & 0.95 \\
SRCTJ1 & 2895.10 & 4079.85 & 1.01 \\
SRCTJ2 & 4023.6 & 5501.23 & 1.01 \\
SRCTJ3 & 5231.77 & 7003.46 & 1.05 \\
SRCTJ4 & 6572.45 & & 0.94 \\
\hline
\end{tabular}

\section{Conclusion}

(1) A numerical finite element model is established to simulate the mechanical behavior of SRCFCST column-reinforced concrete beam framework joints. The FEA results coincide well with the existing test results, which can provide a reference for the nonlinear analysis of similar joints.

(2) On account of uniform distribution of circular steel reinforced around the section and without definite flange and web, the shear mechanism of joints is analyzed on the basis of equivalent CST to rectangular steel tube.

(3) The method for calculating the shear bearing capacities of the joint core area superposed by four parts of concrete inside tube, concrete outside tube, hooping, and steel-reinforced web is proposed; and the corresponding formulas for calculating the shear bearing capacity are established. The calculated results of the formulas coincide well with the existing test results.

\section{Data Availability}

The data used to support the findings of this study are included within the article.

\section{Conflicts of Interest}

The authors declared no potential conflicts of interest with respect to the research, authorship, and/or publication of this article.

\section{Acknowledgments}

The authors disclosed receipt of the following financial support for the research, authorship, and/or publication of this article: this research was supported by the National Key Research and Development Program of China (2016YFC0802205) and the National Natural Science Funds (51778532).

\section{References}

[1] C.-W. Yan and J.-Q. Jia, "Seismic performance of steel reinforced ultra high-strength concrete composite frame joints," Earthquake Engineering and Engineering Vibration, vol. 9, no. 3, pp. 439-448, 2010.

[2] Y. Yang, C.-W. Yan, and J.-J. Jia, "Study on restoring force model of steel reinforced ultra high strength concrete column and concrete beam joints," China Civil Engineering Journal, vol. 47, pp. 193-197, 2014, in Chinese.

[3] Y.-J. Lin, "Experimental study on limit values of axial compression ratio of src columns with circular steel tube," China 
Civil Engineering Journal, vol. 34, no. 6, pp. 23-28, 2001, in Chinese.

[4] J.-Z. Wang, L. Cheng, and M.-L. Sun, "Axial load behavior and strength of tube-confined steel-reinforced short columns with ultra-high-strength concrete," Advances In Structural Engineering, vol. 21, pp. 428-444, 2018.

[5] S. J. Hwang and H. J. Lee, "Analytical model for predicting shear strengths of interior reinforced concrete beam-column joints for seismic resistance," ACI Structural Journal, vol. 97, pp. $35-44,2000$.

[6] C. Lin and J. I. Restrepo, "Seismic behavior and design of reinforced concrete interior beam-column joints," Bulletin of the New Zealand Society For Earthquake, vol. 35, pp. 108-128, 2002.

[7] A. A. Jasim, S. Zhang, and J. Liu, "Shear strength and behavior of tubed reinforced and steel reinforced concrete (TRC and TSRC) short columns," Thin-Walled Structures, vol. 48, no. 3, pp. 191-199, 2010.

[8] A. Pimanmas and P. B. Chaimahawan, "Cyclic Shear Resistance of Expanded Beam-Column Joint," Procedia Engineering, vol. 14, pp. 1292-1299, 2011.

[9] J.-S. Fan and J.-G. Nie, "Seismic behavior of steel reinforced concrete column-steel truss beam hybrid joints," Engineering Structures, vol. 56, pp. 1557-1569, 2013.

[10] C.-C. Chen and Y.-J. Lin, "Behavior and strength of steel reinforced concrete beam-column joints with single-side force inputs," Journal of Constructional Steel, vol. 65, pp. 641-649, 2009.

[11] C.-T. Cheng, C.-F. Chan, and L.-L. Chung, "Seismic behavior of steel beams and CFT column moment-resisting connections with floor slabs," Journal of Constructional Steel Research, vol. 63, pp. 1479-1493, 2007.

[12] L.-H. Han and W. Li, "Seismic performance of CFST column to steel beam joint with RC slab experiments," Journal of Constructional Steel Research, vol. 66, pp. 1374-1386, 2010.

[13] Y. F. Zhang, J. H. Zhao, and C. S. Cai, "Seismic behavior of ring beam joints between concrete-filled twin steel tubes columns and reinforced concrete beams," Engineering Structures, vol. 39, pp. 1-10, 2012.

[14] L.-H. Han, H. Qu, Z. Tao, and Z.-F. Wang, "Experimental behaviour of thin-walled steel tube confined concrete column to RC beam joints under cyclic loading," Thin-Walled Structures, vol. 47, no. 8-9, pp. 847-857, 2009.

[15] J. Nie, Y. Bai, and C. S. Cai, "New connection system for confined concrete columns and beams. I: experimental study," Journal of Structural Engineering, vol. 134, no. 12, pp. 17871799, 2008.

[16] Q.-J. Chen, J. Cai, M. A. Bradford, X. Liu, and Z.-L. Zuo, "Seismic behaviour of a through-beam connection between concrete-filled steel tubular columns and reinforced concrete beams," Engineering Structures, vol. 80, pp. 24-39, 2014.

[17] F.-X. Ding, G.-A. Yin, L.-P. Wang, D. Hu, and G.-Q. Chen, "Seismic performance of a non-through-core concrete between concrete-filled steel tubular columns and reinforced concrete beams," Thin-Walled Structures, vol. 110, pp. 14-26, 2017.

[18] F.-Y. Liao, L.-H. Han, and Z. Tao, "Behaviour of composite joints with concrete encased CFST columns under cyclic loading: Experiments," Engineering Structures, vol. 59, pp. 745-764, 2014.

[19] Q. Wang, Q. Shi, and Y. Tao, "Experimental and numerical studies on the seismic behavior of steel reinforced concrete compression-bending members with new-type section steel," Advances in Structural Engineering, vol. 19, pp. 255-269, 2016.
[20] Q. Wang, Q. Shi, and H. Tian, "Seismic behavior of steel reinforced concrete (SRC) joints with new-type section steel under cyclic loading," Steel and Composite Structures, vol. 19, no. 6, pp. 1561-1580, 2015.

[21] L. Xu and C. K. Lee, "Modeling of two dimensional reinforced concrete beam-column joints subjected to monotonic loading," Advances in Structural Engineering, vol. 18, pp. 14611474, 2015.

[22] A. S. Genikomsou and M. A. Polak, "Finite element analysis of punching shear of concrete slabs using damaged plasticity model in ABAQUS," Engineering Structures, vol. 98, pp. 3848, 2015.

[23] J. Lubliner, J. Oliver, S. Oller, and E. Oñate, "A plastic-damage model for concrete," International Journal of Solids and Structures, vol. 25, no. 3, pp. 299-326, 1989.

[24] GB 50010-2010, Code for Design of Concrete Structures, National standards of People's Republic of China, Beijing, China, 2010, in Chinese.

[25] M.-X. Tao and J.-G. Nie, "Calculational method of joint core shear force in RC frame structures," Journal of Building Strucrures, vol. 37, pp. 242-246, 2016, in Chinese.

[26] J. Lee and G. L. Fenves, "Plastic-damage model for cyclic loading of concrete structures," Journal of Engineering, vol. 124, pp. 892-900, 1998.

[27] J. Xue, L. Zhai, and Y. Bao, "Cyclic loading tests and shear strength of steel reinforced recycled concrete beam-column inner joints," Structural Design of Tall and Special Buildings, vol. 92, pp. 55-68, 2015.

[28] J. Xue, L. Zhai, and Y.-Z. Bao, "Seismic behavior of steelreinforced recycled concrete inner-beam-column connection under low cyclic loads," Advances in Structural Engineering, vol. 21, pp. 631-642, 2018.

[29] Q. Wang, Q. Shi, and H. Tian, "Experimental study on shear capacity of SRC joints with different arrangement and sizes of cross-shaped steel in column," Steel and Composite Structures, vol. 21, no. 2, pp. 267-287, 2016.

[30] GB 50936-2014, Technical Code for Concrete Filled Steel Tubular Structure, National standards of People's Republic of China, Beijing, China, 2014, in Chinese.

[31] C.-W. Yan, J. Li, and J.-Q. Jia, "Experimental research and theoretical analysis on shear strength of steel reinforced ultra high strength concrete frame joint," Journal of Building Structures, vol. 37, pp. 32-39, 2016, in Chinese. 


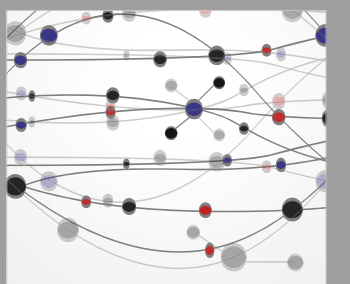

The Scientific World Journal
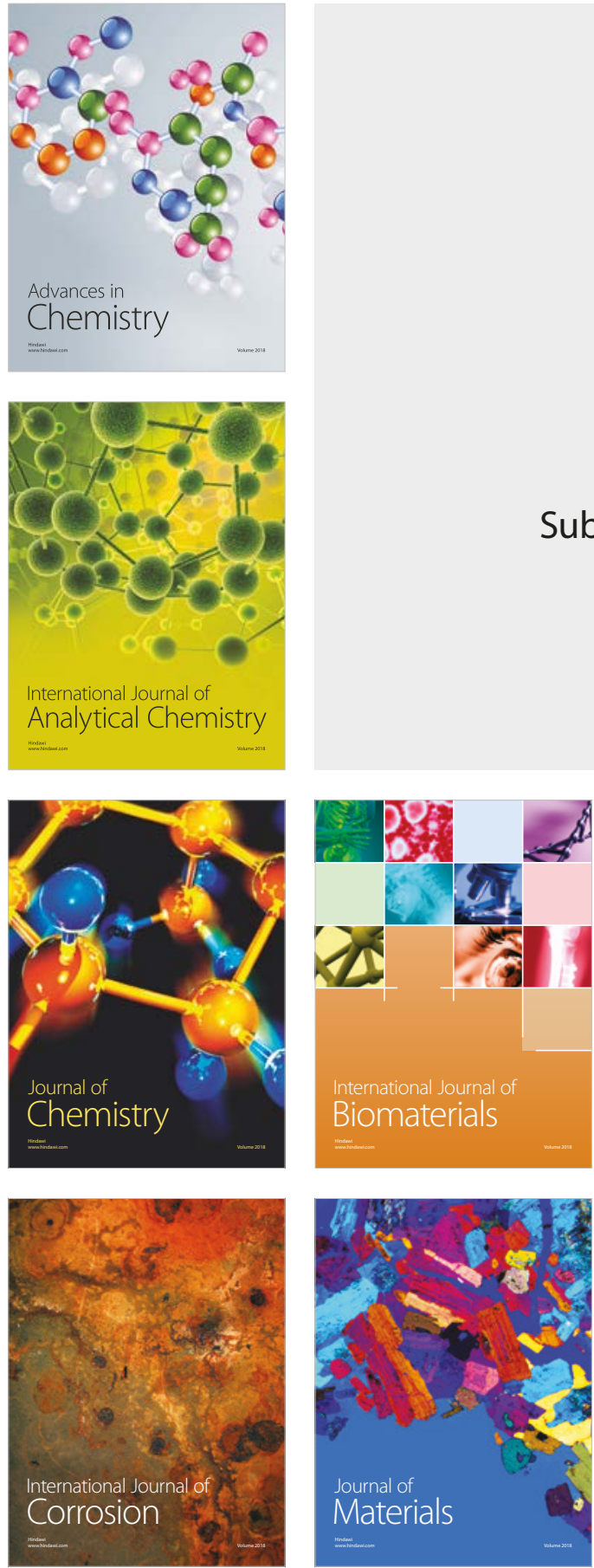

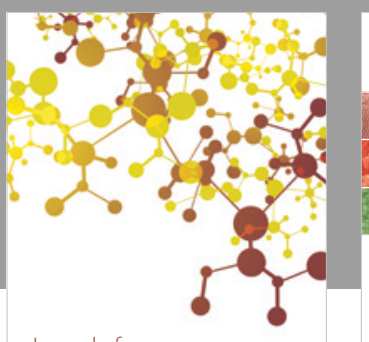

Journal of

Applied Chemistry
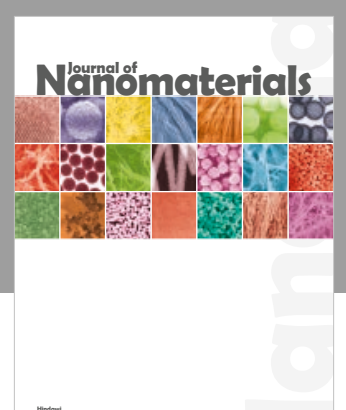

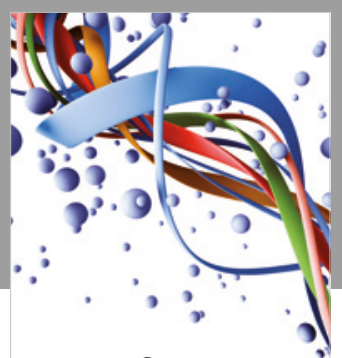

Scientifica

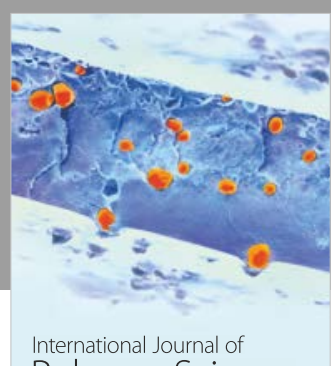

Polymer Science

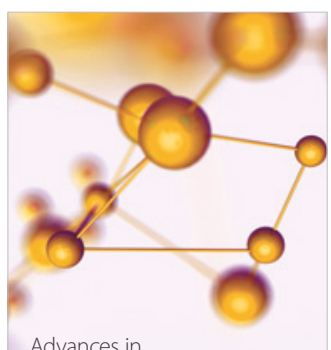

Physical Chemistry
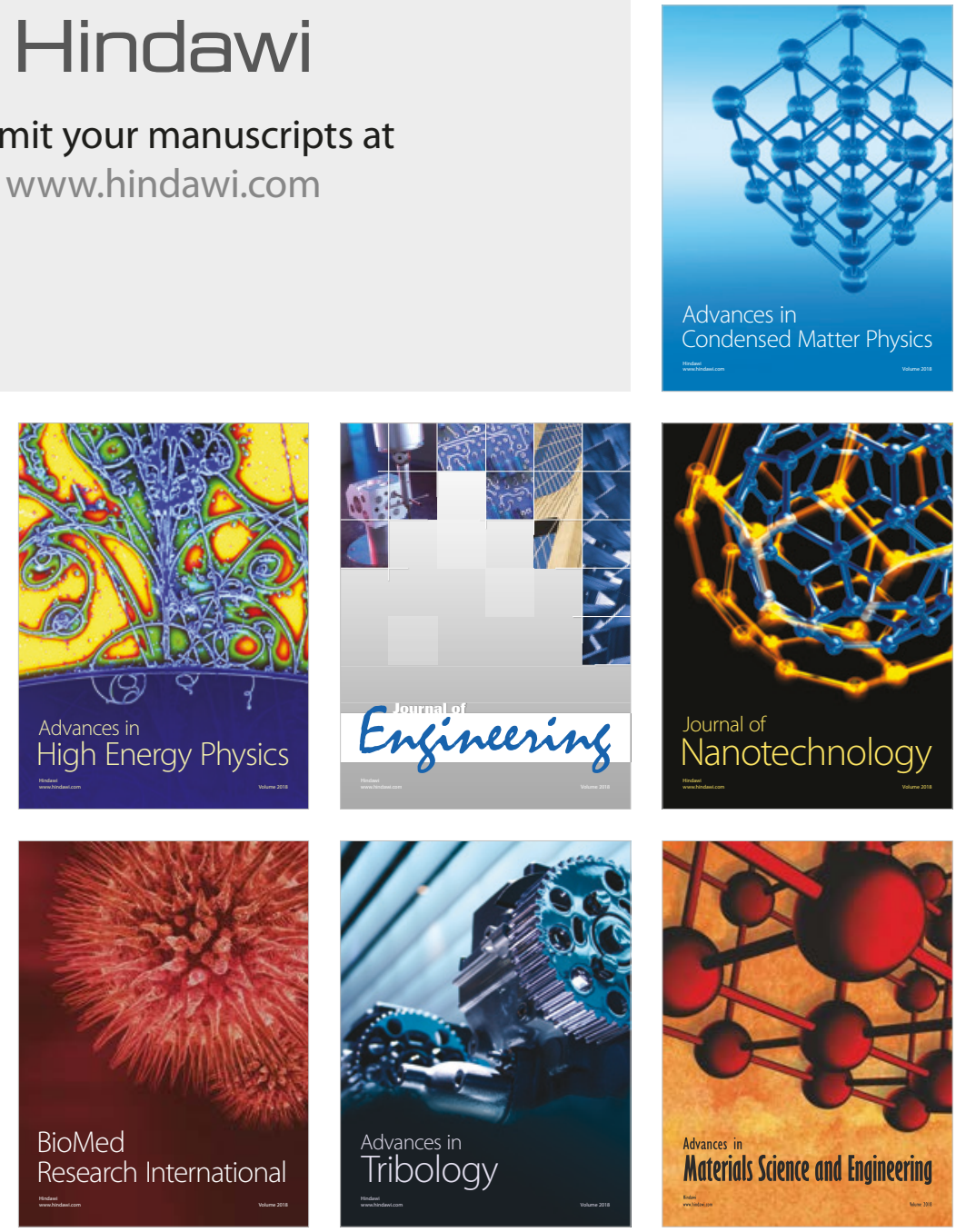